\title{
OPERATING EFFICIENCY ASSESSMENT OF COMMERCIAL BANKS WITH COOPERATIVE-STACKELBERG HYBRID TWO-STAGE DEA
}

\author{
JiANFENG MA* AND TIANMINGDi ZHAO
}

\begin{abstract}
The two-stage Data Envelopment Analysis (DEA) is widely applied to assess the efficiency of commercial banks in recent years. Even though this approach well simulates the sequence of banks production process, the independent operations within sub-stages are generally ignored, and the cooperative or non-cooperative relations between sub-stages are usually investigated separately. Commercial banking production system, however, has complex internal structure within which parallel and series structure can co-exist, and cooperative relations may concurrently occur with non-cooperative ones. In this paper, we develop a hybrid two-stage DEA to consider simultaneously the series-parallel internal structure and the cooperative-Stackelberg relations between sub-stages. The data of 19 Chinese listed commercial banks are used to show the abilities of the proposed models. This approach represents a powerful and flexible efficiency measurement implement that can be applied when the system in question has a complex internal structure in terms of both sub-systems features and sub-systems relations.
\end{abstract}

Mathematics Subject Classification. 90B30, 91-10.

Received April 21, 2021. Accepted September 26, 2021.

\section{INTRODUCTION}

Introduced by Charnes et al. [8], Data Envelopment Analysis (DEA) is a non-parametric mathematical method for assessing the relative efficiency of a set of homogenous Decision Making Units (DMUs). The banking sector is a popular field for methodological and applied researches involving DEA techniques [15]. The study of Sherman and Gold [36] is one of the first studies that apply the CCR model [8] to evaluate operating efficiency of banks. The authors point out that DEA results provide meaningful insights not available from other techniques. Over the last three decades, the banking industry has been probably becoming the most heavily studied by DEA approach of all business sectors [31].

The traditional CCR model [8] treats DMU as a black box of converting initial inputs to final outputs. Without considering the internal structure, the black box approach could not give specific information regarding the sources of inefficiency within DMUs [22], and tends to produce inaccurate efficiency scores or misleading results [16]. In classic two-stage DEA, DMU is considered as a system having two-stage internal structure, in which the initial inputs are transformed into intermediate measures [9] through the first stage, and then the intermediate measures are developed into final output in the second stage. Two-stage DEA simulates a general internal structure of the production process and provides the possibility to assess the efficiency of the whole

Keywords. Commercial bank, two-stage sSystem, efficiency evaluation, data envelopment analysis.

School of Economics and Management, University of Science and Technology Beijing, Beijing100083, P.R. China.

*Corresponding author: majf@ustb.edu.cn 
system and to decompose the overall efficiency into the efficiency of each sub-stage $[10,18,33]$.

The significant applications of two-stage DEA in banking industry have been rising since the late 1990s. For example, Athanassopoulos [5] develop a two-stage DEA model to assess the operating efficiency and the quality of provided services of 68 commercial bank branches in Greece. Seiford and Zhu [34] propose a well-known two-stage DEA model that separates profitability and marketability to examine the performance of the top 55 U.S. commercial banks and indicate that the developed model is suitable to identify areas for improved bank performance over the production process. Similarly, Luo [27] evaluates the profitability and marketability performances of 245 large banks in the U.S.

The earlier studies have explicitly described the basic two-stage internal structure as deposit-producing stage and profit-earning stage linked by deposits generated from the first one. Two-stage DEA has been considerably developed in the applications to the banking efficiency measurement after 2010. Table 1 (Continued Table) summarize some of these studies.

Lozano [26] summarized more than twenty network DEA applications in the efficiency measurement of banks or bank branches, and the author indicated that most studies consider two-stage systems in series. Nevertheless, this structural feature presents certain insufficiencies in the banks performance evaluation. For example, if the operations within a sub-stage are also ordered in series, the problem can be mathematically formulated to a three-stage DEA modelling such as a network DEA framework proposed by Matthews [28] or to a more general multi-stage systems case studied by Kao [17]; but, if the internal operations of a sub-stage are organized in parallel and effectuated independently, how to evaluate and decompose the efficiency of the system with respecting the different efficiency formation mechanisms?

Indeed, there are a few studies concerning the above issues. For example, Naini et al. [30] consider the production process of bank as a two-stage system where the second stage includes two parallel sub-stages sharing intermediate measures. Ebrahimnejad et al. [12] propose a three-stage DEA model to evaluate the efficiencies of a banking system where the two first independent parallel stages are linked to the third stage. However, a common inadequacy in the two studies is that they do not offer any measures to assess the overall efficiency of system, so the overall efficiency formation mechanism is not involved in their modelling. Moreover, the relation between the deposit-producing stage and profit-earning stage is usually considered as cooperative. That is, the two stages are supposed to optimize the efficiencies simultaneously in the condition that the overall efficiency of the production system is maximized [23], and the intermediate measures are therefore to be given the same weights in both stages. However, the decision makers may prefer to give priority to one of the two stages, which will implicate potential conflicts between the two stages arising from the intermediate measures [34]. The latter situation is studied by the leader-follower or Stackelberg game EDA [24]. So, how to measure the overall efficiency and decompose it into the efficiency of each sub-system, if the cooperative and non-cooperative relations coexist in a parallel-series production system? What are the strategic implications for managers according to the cooperative situation, non-cooperative situation, and different leader-follower positions of two sub-stages?

With these questions in mind, we attempt to make up for the insufficiency of the existing two-stage DEA approaches by developing a set of cooperative-Stackelberg hybrid two-stage DEA models with consideration of complex internal structure and relations. The remainder of this paper is organized as follows. The methodology section presents the hybrid two-stage DEA models with its efficiency assessment and decomposition procedures in cooperation and cooperation-Stackelberg situations. In the illustrative application section, our proposed approach is applied to the data of 19 Chinese listed commercial banks. Section 4 outlines conclusions and future research directions.

\section{Methodology}

The primary task of commercial bank is to transform savings into investments and get profits as efficiently as possible. A certain sequence exists in collecting savings deposits and granting loans in the production process. Besides, the savings of commercial banks are derived mainly from household and business, and the exploitations 
TABLE 1. Summary of two-stage DEA applications to the efficiency assessment of bank industry.

\begin{tabular}{|c|c|c|c|c|}
\hline Authors & Models & Inputs & $\begin{array}{l}\text { Intermediate } \\
\text { measures, }\end{array}$ & Outputs \\
\hline $\begin{array}{l}\text { Zha and Liang } \\
{[45]}\end{array}$ & $\begin{array}{l}\text { Two-stage } \\
\text { DEA with } \\
\text { shared inputs. }\end{array}$ & $\begin{array}{l}\text { Employees, } \\
\text { Assets, Equity. }\end{array}$ & $\begin{array}{l}\text { Revenues, } \\
\text { Profits. }\end{array}$ & $\begin{array}{l}\text { Market value, } \\
\text { Earnings, } \\
\text { Returns. }\end{array}$ \\
\hline Tsolas[40] & $\begin{array}{l}\text { Independent } \\
\text { two-stage } \\
\text { DEA. }\end{array}$ & $\begin{array}{l}\text { Personnel and Rental } \\
\text { expenses, Other } \\
\text { operational expenses, } \\
\text { Depreciation. }\end{array}$ & $\begin{array}{l}\text { Interest and non- } \\
\text { interest income, } \\
\text { Loans, } \\
\text { Commission. }\end{array}$ & Net income. \\
\hline $\begin{array}{l}\text { Fukuyama and } \\
\text { Matousek [13] }\end{array}$ & $\begin{array}{l}\text { Slacks-based } \\
\text { two-stage DEA. }\end{array}$ & $\begin{array}{l}\text { Labor, } \\
\text { Capital. }\end{array}$ & Deposits. & $\begin{array}{l}\text { Loans, } \\
\text { Securities. }\end{array}$ \\
\hline $\begin{array}{l}\text { Ashrafi and } \\
\text { Jaafar }[4]\end{array}$ & $\begin{array}{l}\text { Two-stage DEA } \\
\text { with undesirable } \\
\text { input-outputs. }\end{array}$ & $\begin{array}{l}\text { Personnel, } \\
\text { Expenditures, } \\
\text { Depreciation. }\end{array}$ & Resources. & $\begin{array}{l}\text { Income, } \\
\text { Usages, } \\
\text { Receivable. }\end{array}$ \\
\hline $\begin{array}{l}\text { Avkiran and } \\
\text { McCrystal [6] }\end{array}$ & $\begin{array}{l}\text { Two-stage DEA } \\
\text { with add. input } \\
\text { and intermediate } \\
\text { measures. }\end{array}$ & $\begin{array}{l}\text { Capital, Labor, } \\
\text { Customer service } \\
\text { training. }\end{array}$ & $\begin{array}{l}\text { Number of } \\
\text { referrals, } \\
\text { Number of } \\
\text { transactions. }\end{array}$ & $\begin{array}{l}\text { Number of } \\
\text { referral sales. }\end{array}$ \\
\hline $\begin{array}{l}\text { Akther } \\
\text { et al. [1] }\end{array}$ & $\begin{array}{l}\text { Two-stage DEA } \\
\text { with undesirable } \\
\text { outputs. }\end{array}$ & $\begin{array}{l}\text { Employees, Capital, } \\
\text { Equity, Bad loans. }\end{array}$ & Deposits. & $\begin{array}{l}\text { Loans, } \\
\text { Bad loans, } \\
\text { Investments. }\end{array}$ \\
\hline Zhou et al. [47] & $\begin{array}{l}\text { Nash bargaining } \\
\text { two-stage DEA. }\end{array}$ & $\begin{array}{l}\text { Employees, Fixed } \\
\text { assets, Expenses. }\end{array}$ & $\begin{array}{l}\text { Credit, } \\
\text { Interbank loans. }\end{array}$ & $\begin{array}{l}\text { Loans, } \\
\text { Profits. }\end{array}$ \\
\hline Wang et al. [42] & $\begin{array}{l}\text { Additive two- } \\
\text { stage DEA. }\end{array}$ & $\begin{array}{l}\text { Labor, } \\
\text { Fixed assets. }\end{array}$ & Deposits. & $\begin{array}{l}\text { Interest income, } \\
\text { Bad loans. }\end{array}$ \\
\hline $\begin{array}{l}\text { Wanke and } \\
\text { Barros [41] }\end{array}$ & $\begin{array}{l}\text { Centralized two- } \\
\text { stage DEA. }\end{array}$ & $\begin{array}{l}\text { Number of branches, } \\
\text { Employees. }\end{array}$ & $\begin{array}{l}\text { Administrative } \\
\text { Personnel } \\
\text { expenses. }\end{array}$ & $\begin{array}{l}\text { Permanent } \\
\text { assets, } \\
\text { Equity. }\end{array}$ \\
\hline $\begin{array}{l}\text { Kwon and } \\
\text { Lee }[20]\end{array}$ & $\begin{array}{l}\text { Two-stage DEA- } \\
\text { neural network. }\end{array}$ & $\begin{array}{l}\text { Employees, Equity, } \\
\text { Expenses. }\end{array}$ & $\begin{array}{l}\text { Deposits, Loans, } \\
\text { Investments. }\end{array}$ & Profit. \\
\hline Liu et al. [25] & $\begin{array}{l}\text { Two-stage DEA } \\
\text { with undesirable } \\
\text { in-inter.-output. }\end{array}$ & $\begin{array}{l}\text { Employees, } \\
\text { Fixed assets, } \\
\text { Operating expenses. }\end{array}$ & $\begin{array}{l}\text { Profits, Loans, } \\
\text { Non-performing } \\
\text { loans. }\end{array}$ & $\begin{array}{l}\text { Market value, } \\
\text { Earnings } \\
\text { per share, } \\
\text { Volatility. }\end{array}$ \\
\hline $\begin{array}{l}\text { Amirteimoori } \\
\text { et al. }[2]\end{array}$ & $\begin{array}{l}\text { Two-stage DEA } \\
\text { with shared inputs } \\
\text { and intermediate } \\
\text { measures. }\end{array}$ & $\begin{array}{l}\text { Fund from customers, } \\
\text { Number of check } \\
\text { accounts, } \\
\text { Operating costs. }\end{array}$ & Deposits. & $\begin{array}{l}\text { Number of } \\
\text { transaction, } \\
\text { Loans, Profits, } \\
\text { Deposits. }\end{array}$ \\
\hline Chen et al. [11] & $\begin{array}{l}\text { Envelopment and } \\
\text { multiplier-based } \\
\text { two-stage DEA. }\end{array}$ & $\begin{array}{l}\text { Employees, } \\
\text { Equality. }\end{array}$ & $\begin{array}{l}\text { Revenues, } \\
\text { Profits. }\end{array}$ & Returns. \\
\hline Shi et al. [37] & $\begin{array}{l}\text { Two-stage } \\
\text { cost efficiency } \\
\text { DEA model. }\end{array}$ & $\begin{array}{l}\text { Fixed assets, Labor } \\
\text { and other operating } \\
\text { expense. }\end{array}$ & Deposits. & $\begin{array}{l}\text { Non-interest } \\
\text { income, } \\
\text { Interest income. }\end{array}$ \\
\hline $\begin{array}{l}\text { Fukuyama and } \\
\text { Matousek [14] }\end{array}$ & $\begin{array}{l}\text { Two-stage DEA } \\
\text { with jointly and } \\
\text { non-jointly good } \\
\text { and bed outputs. }\end{array}$ & Labor, Capital. & Deposits. & $\begin{array}{l}\text { Loans, non- } \\
\text { performing loans, } \\
\text { Securities } \\
\text { investments. }\end{array}$ \\
\hline
\end{tabular}


TABLE 1. continued.

\begin{tabular}{|c|c|c|c|c|}
\hline Authors & Models & Inputs & $\begin{array}{l}\text { Intermediate } \\
\text { measures, }\end{array}$ & Outputs \\
\hline An et al. [3] & $\begin{array}{l}\text { Two-stage DEA } \\
\text { fair efficiency } \\
\text { decomposition. }\end{array}$ & $\begin{array}{l}\text { Employees, } \\
\text { Expenses, } \\
\text { Fixed assets. }\end{array}$ & $\begin{array}{l}\text { Credits, } \\
\text { Interbank } \\
\text { loans. }\end{array}$ & $\begin{array}{l}\text { Loans, } \\
\text { Profits. }\end{array}$ \\
\hline Kwon et al. [21] & $\begin{array}{l}\text { BPNN approach } \\
\text { with two- } \\
\text { stage DEA. }\end{array}$ & $\begin{array}{l}\text { Operational } \\
\text { expenses, } \\
\text { Equity. }\end{array}$ & Deposits. & $\begin{array}{l}\text { Loans, } \\
\text { Investments, } \\
\text { Revenue. }\end{array}$ \\
\hline $\begin{array}{l}\text { Kourtzidis } \\
\text { et al. }[19]\end{array}$ & $\begin{array}{l}\text { Two-stage DEA } \\
\text { with Weight } \\
\text { Assurance model. }\end{array}$ & $\begin{array}{l}\text { Employees, } \\
\text { Total assets. }\end{array}$ & Deposits. & $\begin{array}{l}\text { Loans, } \\
\text { Securities. }\end{array}$ \\
\hline $\begin{array}{l}\text { Tavakoli and } \\
\text { Mostafaee[38] }\end{array}$ & $\begin{array}{l}\text { Two-stage DEA } \\
\text { in Free Disposal } \\
\text { Hull (FDH). }\end{array}$ & $\begin{array}{l}\text { Human resources, } \\
\text { Fixed assets, } \\
\text { No. of branches. }\end{array}$ & Deposits. & Profits. \\
\hline $\begin{array}{l}\text { Mehdizadeh, } \\
\text { et al. [29] }\end{array}$ & $\begin{array}{l}\text { Two-stage DEA } \\
\text { with stochastic } \\
\text { data. }\end{array}$ & $\begin{array}{l}\text { Employees, } \\
\text { Fixed assets, } \\
\text { Expenses. }\end{array}$ & $\begin{array}{l}\text { Deposits, } \\
\text { Interbank } \\
\text { Deposits. }\end{array}$ & $\begin{array}{l}\text { Loan, } \\
\text { Profits. }\end{array}$ \\
\hline $\begin{array}{l}\mathrm{Xu} \text { and } \\
\text { Zhou [43] }\end{array}$ & $\begin{array}{l}\text { Two-stage } \\
\text { AR-DEA } \\
\text { model. }\end{array}$ & $\begin{array}{l}\text { Total assets, } \\
\text { Labors, Operating } \\
\text { expenses. }\end{array}$ & Deposits. & $\begin{array}{l}\text { Interest and non- } \\
\text { incomes, Non } \\
\text { performing loans. }\end{array}$ \\
\hline $\begin{array}{l}\text { Shahbazifar, } \\
\text { et al. [35] }\end{array}$ & $\begin{array}{l}\text { Group efficiency } \\
\text { of two-stage } \\
\text { DEA. }\end{array}$ & $\begin{array}{l}\text { Personnel costs, } \\
\text { Paid interests. }\end{array}$ & $\begin{array}{l}\text { Raised funds, } \\
\text { related to currency } \\
\text { transactions. }\end{array}$ & $\begin{array}{l}\text { Loans, } \\
\text { Common incomes. }\end{array}$ \\
\hline An et al. [3] & $\begin{array}{l}\text { Two-stage } \\
\text { closest target } \\
\text { DEA model. }\end{array}$ & $\begin{array}{l}\text { Operation costs, } \\
\text { Interest costs, } \\
\text { Labors. }\end{array}$ & Deposits. & $\begin{array}{l}\text { Interest income, } \\
\text { Non-interest } \\
\text { income. }\end{array}$ \\
\hline
\end{tabular}

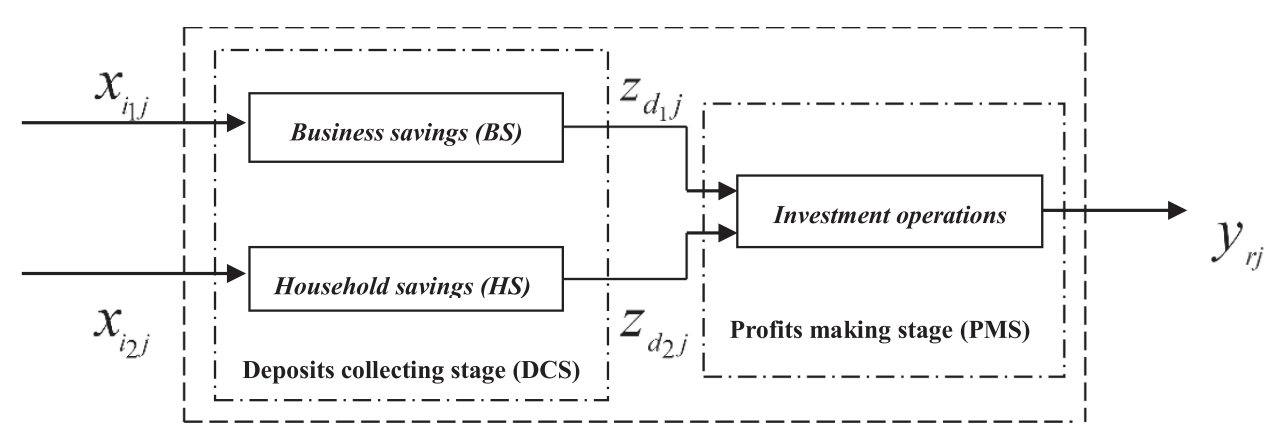

FiguRE 1. Structure of bank's hybrid two-stage production system.

of these two sources are usually conducted independently. According to these procedural characteristics, we propose to consider banking production process as a two-stage system comprised of three sub-systems as shown in Figure 1.

More specifically, we regard the commercial bank having a hybrid two-stage production system as a set of homogeneous DMUs, denoted as $\operatorname{DMU}_{j}(j=1, \ldots, n)$. For any commercial bank $j,(j=1, \ldots, n)$, the deposits collecting stage (DCS) is comprised of two independent sub-systems in parallel where the business savings services system (BS) consumes $I_{1}$ operational costs $x_{i_{1} j},\left(i_{1}=1, \ldots, I_{1}\right)$ to generate $D_{1}$ 
business deposits $z_{d_{1} j},\left(d_{1}=1, \ldots, D_{1}\right)$, and the household savings services system (HS) uses $I_{2}$ operational $\operatorname{costs} x_{i_{2} j},\left(i_{2}=1, \ldots, I_{2}\right)$ to yield $D_{2}$ household deposits $z_{d_{2} j},\left(d_{2}=1, \ldots, D_{2}\right)$.

The DCS is then linked to profits making stage (PMS) in series by the outputs from DCS $z_{d_{1} j},\left(d_{1}=1, \ldots, D_{1}\right)$ and $z_{d_{2} j},\left(d_{2}=1, \ldots, D_{2}\right)$, referred to as intermediate measures [9] or links [39]. PMS employs both household and business savings to yield $S$ final outputs $y_{r j},(r=1, \ldots, S)$.

Let $v_{i_{1}}$ and $v_{i_{2}}$ denote the weights associated with the inputs $x_{i_{1} j},\left(i_{1}=1, \ldots, I_{1}\right)$ and $x_{i_{2} j},\left(i_{2}=1, \ldots, I_{2}\right)$ , respectively. Since the intermediate measures play a dual role in DCS and PMS, we denote $u_{d_{1}}^{1}$ and $u_{d_{2}}^{1}$ as the weights on the outputs flowing from DCS, and $u_{d_{1}}^{2}$ and $u_{d_{2}}^{2}$ as the weights on the intermediate measures entering PMS, respectively. The weight $u_{r}$ is given to $y_{r j},(r=1, \ldots, S)$.

\subsection{Cooperative hybrid two-stage DEA appraoch}

\subsubsection{Cooperative hybrid two-stage DEA models}

We start with the CCR efficiency estimation of BS and HS for $\mathrm{DMU}_{0}$ by the following models (1) and (2), respectively.

$$
\begin{aligned}
& \theta_{0}^{1.1}=\max \frac{\sum_{d_{1}=1}^{D_{1}} u_{d_{1}}^{1} z_{d_{1} 0}}{\sum_{i_{1}=1}^{I_{1}} v_{i_{1}} x_{i_{1} 0}} \\
& \text { s.t. } \frac{\sum_{d_{1}=1}^{D_{1}} u_{d_{1}}^{1} z_{d_{1} j}}{\sum_{i_{1}=1}^{I_{1}} v_{i_{1}} x_{i_{1} j}} \leq 1, \quad j=1, \ldots, n \\
& u_{d_{1}}^{1}, v_{i_{1}} \geq 0, d_{1}=1, \ldots, D_{1}, i_{1}=1, \ldots, I_{1} . \\
& \theta_{0}^{1.2}=\max \frac{\sum_{d_{2}=1}^{D_{2}} u_{d_{2}}^{1} z_{d_{2} 0}}{\sum_{i_{2}=1}^{I_{2}} v_{i_{2}} x_{i_{2} 0}} \\
& \begin{array}{ll}
\text { s.t. } & \frac{\sum_{d_{2}=1}^{D_{2}} u_{d_{2}}^{1} z_{d_{2} j}}{\sum_{i_{2}}=1} v_{i_{2}} x_{i_{2} j} \\
& u_{d_{2}}^{1}, v_{i_{2}} \geq 0, d_{2}=1, \ldots, D_{2}, i_{2}=1, \ldots, I_{2} .
\end{array}
\end{aligned}
$$

According to the assumptions about the internal structure, BS and HS are organized in parallel and operate independently. Since there are no trade-offs between BS and HS, we propose to define the efficiency of DCS, denoted as $\theta_{0}^{1}$, as a weighted sum of efficiencies of BS and HS, denoted as $\theta_{0}^{1.1}$ and $\theta_{0}^{1.2}$, respectively.

$$
\theta_{0}^{1}=\max \left(w_{1} \theta_{0}^{1.1}+w_{2} \theta_{0}^{1.2}\right)
$$

where $w_{1}$ and $w_{2}$ are the associated weights to $\theta_{0}^{1.1}$ and $\theta_{0}^{1.2}$ such that $w_{1}+w_{2}=1$. In Chen et al. [10], these weights are specified as the proportions of total weighted resources devoted to the respective sub-systems.

$$
w_{1}=\frac{\sum_{i_{1}=1}^{I_{1}} v_{i_{1}} x_{i_{1} 0}}{\sum_{i_{1}=1}^{I_{1}} v_{i_{1}} x_{i_{1} 0}+\sum_{i_{2}=1}^{I_{2}} v_{i_{2}} x_{i_{2} 0}}, \text { and } w_{2}=\frac{\sum_{i_{2}=1}^{I_{2}} v_{i_{2}} x_{i_{2} 0}}{\sum_{i_{1}=1}^{I_{1}} v_{i_{1}} x_{i_{1} 0}+\sum_{i_{2}=1}^{I_{2}} v_{i_{2}} x_{i_{2} 0}} .
$$

Therefore, viewed from the point of internal resources allocation, $w_{1}$ and $w_{2}$ reasonably represent the relative contribution or importance of the efficiencies of BS and HS to the performance of DCS. With models (2.1) and (2.2), and formulas (2.3) and (2.4), the efficiency of DCS can be evaluated by model (2.5):

$$
\begin{aligned}
\theta_{0}^{1}=\max & \frac{\sum_{d_{1}=1}^{D_{1}} u_{d_{1}}^{1} z_{d_{1} 0}+\sum_{d_{2}=1}^{D_{2}} u_{d_{2}}^{1} z_{d_{2} 0}}{\sum_{i_{1}=1}^{I_{1}} v_{i_{1}} x_{i_{1} 0}+\sum_{i_{2}=1}^{I_{2}} v_{i_{2}} x_{i_{2} 0}} \\
\text { s.t. } & \frac{\sum_{d_{1}=1}^{D_{1}} u_{d_{1}}^{1} z_{d_{1} j}}{\sum_{i_{1}=1}^{I_{1}} v_{i_{1}} x_{i_{1} j}} \leq 1, \quad j=1, \ldots, n
\end{aligned}
$$




$$
\begin{aligned}
& \frac{\sum_{d_{2}=1}^{D_{2}} u_{d_{2}}^{1} z_{d_{2} j}}{\sum_{i_{2}=1}^{I_{2}} v_{i_{2}} x_{i_{2} j}} \leq 1, \quad j=1, \ldots, n \\
& u_{d_{1}}^{1}, u_{d_{2}}^{1}, v_{i_{1}}, v_{i_{2}} \geq 0, d_{1}=1, \ldots, D_{1}, d_{2}=1, \ldots, D_{2}, \\
& i_{1}=1, \ldots, I_{1}, i_{2}=1, \ldots, I_{2} .
\end{aligned}
$$

Note that the definition and procedure mentioned above are based on the thoughts of additive DEA method [10], which is developed originally to evaluate the efficiency of a two-stage system in series. However, considering that the intermediate measures are concerned in view of resources rather than its link role, it is appropriate to apply the additive method to estimate the efficiency of DCS.

The efficiency of PMS for $\mathrm{DMU}_{0}$, denoted as $\theta_{0}^{2}$, can be calculated via the following fractional model (2.6):

$$
\begin{aligned}
& \theta_{0}^{2}=\max \frac{\sum_{r=1}^{S} u_{r} y_{r 0}}{\sum_{d_{1}=1}^{D_{1}} u_{d_{1}}^{2} z_{d_{1} 0}+\sum_{d_{2}=1}^{D_{2}} u_{d_{2}}^{2} z_{d_{2} 0}} \\
& \text { s.t. } \frac{\sum_{r=1}^{S} u_{r} y_{r j}}{\sum_{d_{1}=1}^{D_{1}} u_{d_{1}}^{2} z_{d_{1} j}+\sum_{d_{2}=1}^{D_{2}} u_{d_{2}}^{2} z_{d_{2} j}} \leq 1, j=1, \ldots, n \\
& u_{r}, u_{d_{1}}^{2}, u_{d_{2}}^{2} \geq 0, r=1, \ldots, S, d_{1}=1, \ldots, D_{1}, d_{2}=1, \ldots, D_{2} .
\end{aligned}
$$

Suppose that relations among all sub-systems within the production system are cooperative. That is, with given initial inputs $\sum_{i_{1}=1}^{I_{1}} v_{i_{1}} x_{i_{1} j}$ and $\sum_{i_{2}=1}^{I_{2}} v_{i_{2}} x_{i_{2} j}$, the DCS will yield optimal $\sum_{d_{1}=1}^{D_{1}} u_{d_{1}} z_{d_{1} j}$ and $\sum_{d_{2}=1}^{D_{2}} u_{d_{2}} z_{d_{2} j}$, to maximize the overall efficiency. Therefore, the weights associated with intermediate measures should be identical no matter they play the role of output from DCS or input to PMS, i.e., $u_{d_{1}}^{1}=u_{d_{1}}^{2}=u_{d_{1}}$ and $u_{d_{2}}^{1}=u_{d_{2}}^{2}=u_{d_{2}}[18,24]$. We define then the overall efficiency, denoted as $\theta_{0}^{\text {overall }}$, as the product of efficiencies of DCS and PMS according to the thoughts of multiplicative DEA method [18].

$$
\theta_{0}^{\text {overall }}=\max \theta_{0}^{1} \cdot \theta_{0}^{2}
$$

Thus, the overall efficiency of $\mathrm{DMU}_{0}$ can be obtained by model (2.8):

$$
\begin{aligned}
& \theta_{0}^{\text {overall }}=\max \frac{\sum_{r=1}^{S} u_{r} y_{r 0}}{\sum_{i_{1}=1}^{I_{1}} v_{i_{1}} x_{i_{1} 0}+\sum_{i_{2}=1}^{I_{2}} v_{i_{2}} x_{i_{2} 0}} \\
& \text { s.t. } \frac{\sum_{d_{1}=1}^{D_{1}} u_{d_{1}} z_{d_{1} j}}{\sum_{i_{1}=1}^{I_{1}} v_{i_{1}} x_{i_{1} j}} \leq 1, j=1, \ldots, n \\
& \frac{\sum_{d_{2}=1}^{D_{2}} u_{d_{2}} z_{d_{2} j}}{\sum_{i_{2}=1}^{I_{2}} v_{i_{2}} x_{i_{2} j}} \leq 1, \quad j=1, \ldots, n \\
& \frac{\sum_{r=1}^{S} u_{r} y_{r j}}{\sum_{d_{1}=1}^{D_{1}} u_{d_{1}} z_{d_{1} j}+\sum_{d_{2}=1}^{D_{2}} u_{d_{2}} z_{d_{2} j}} \leq 1, j=1, \ldots, n \\
& u_{r}, u_{d_{1}}, u_{d_{2}}, v_{i_{1}}, v_{i_{2}} \geq 0, r=1, \ldots, S, d_{1}=1, \ldots, D_{1}, d_{2}=1, \ldots, D_{2}, \\
& i_{1}=1, \ldots, I_{1}, i_{2}=1, \ldots, I_{2} .
\end{aligned}
$$

By using the Charnes-Cooper transformation [7], model (2.8) can be transformed into program (9): 


$$
\begin{aligned}
& \theta_{0}^{\text {overall }}=\max \sum_{r=1}^{S} \mu_{r} y_{r 0} \\
& \text { s.t. } \quad \sum_{d_{1}=1}^{D_{1}} \mu_{d_{1}} z_{d_{1} j}-\sum_{i_{1}=1}^{I_{1}} \nu_{i_{1}} x_{i_{1} j} \leq 0, \quad j=1, \ldots, n \\
& \sum_{d_{2}=1}^{D_{2}} \mu_{d_{2}} z_{d_{2} j}-\sum_{i_{2}=1}^{I_{2}} \nu_{i_{2}} x_{i_{2} j} \leq 0, j=1, \ldots, n \\
& \sum_{r=1}^{S} \mu_{r} y_{r j}-\sum_{d_{1}=1}^{D_{1}} \mu_{d_{1}} z_{d_{1} j}-\sum_{d_{2}=1}^{D_{2}} \mu_{d_{2}} z_{d_{2} j} \leq 0, j=1, \ldots, n \\
& \sum_{i_{1}=1}^{I_{1}} \nu_{i_{1}} x_{i_{1} 0}+\sum_{i_{2}=1}^{I_{2}} \nu_{i_{2}} x_{i_{2} 0}=1 \\
& \mu_{r}, \mu_{d_{1}}, \mu_{d_{2}}, \nu_{i_{1}}, \nu_{i_{2}} \geq 0, r=1, \ldots, S, d_{1}=1, \ldots, D_{1}, d_{2}=1, \ldots, D_{2}, \\
& i_{1}=1, \ldots, I_{1}, i_{2}=1, \ldots, I_{2} .
\end{aligned}
$$

The overall efficiency and the efficiencies of sub-systems can be calculated with the optimal solution to model (2.9). However, the uniqueness of optimal solution for model (2.9) is not guaranteed, and the decomposition of the overall efficiency as the product of the efficiencies of DCS and PMS should not be necessarily unique in consequence.

Moreover, it is also uncertain to obtain a uniqueness of optimal solution for model (2.5), which will make the unique efficiency decomposition for all sub-systems more complicated. As we mentioned above, sub-stages and sub-systems of the banks production system will collaborate to achieve a maximal overall efficiency in cooperative case. That is, the cooperative situation implicates that efficiency scores of sub-stage or sub-system should be at the same level whether the decision is in favour of themself or the others. In view of these, we propose a procedure of addressing the unique efficiency decomposition issues in the next sub-section.

\subsubsection{Efficiency decomposition procedure}

With the optimal overall efficiency obtained from model (2.9), denoted as $\theta_{0}^{\text {overall* }}$, we calculate either DCS efficiency $\theta_{0}^{1+}$ or PMS efficiency $\theta_{0}^{2+}$ in the most favorable manner to the stage respectively, and then derive the minimal efficiencies of the corresponding stage $\theta_{0}^{2-}$ or $\theta_{0}^{1-}$ accordingly. If $\theta_{0}^{1+}=\theta_{0}^{1-}$ or $\theta_{0}^{2+}=\theta_{0}^{2-}$, unique efficiency decomposition for DCS and PMS is achieved, i.e., $\theta_{0}^{1+}=\theta_{0}^{1-}=\theta_{0}^{1 *}$ and $\theta_{0}^{2+}=\theta_{0}^{2-}=\theta_{0}^{2 *}$. where the "*” signifies the optimal efficiency level.

After that, we will determine either the largest efficiency score of BS $\theta_{0}^{1.1+}$ or that of HS $\theta_{0}^{1.2+}$, and derive the minimal $\theta_{0}^{1.2-}$ or $\theta_{0}^{1.1-}$ within DCS. Finally, we have unique efficiency decomposition for all stages and sub-systems if $\theta_{0}^{1.1+}=\theta_{0}^{1.1-}=\theta_{0}^{1.1 *}$ and $\theta_{0}^{1.2+}=\theta_{0}^{1.2-}=\theta_{0}^{1.2 *}$.

Suppose firstly that the DCS is to be given pre-emptive priority, its maximal efficiency can be calculated by solving program (10):

$$
\begin{aligned}
\theta_{0}^{1+}=\max & \sum_{d_{1}=1}^{D_{1}} \mu_{d_{1}} z_{d_{1} 0}+\sum_{d_{2}=1}^{D_{2}} \mu_{d_{2}} z_{d_{2} 0} \\
\text { s.t. } \quad & \sum_{d_{1}=1}^{D_{1}} \mu_{d_{1}} z_{d_{1} j}-\sum_{i_{1}=1}^{I_{1}} \nu_{i_{1}} x_{i_{1} j} \leq 0, \quad j=1, \ldots, n \\
& \sum_{d_{2}=1}^{D_{2}} \mu_{d_{2}} z_{d_{2} j}-\sum_{i_{2}=1}^{I_{2}} \nu_{i_{2}} x_{i_{2} j} \leq 0, j=1, \ldots, n \\
& \sum_{r=1}^{S} \mu_{r} y_{r j}-\sum_{d_{1}=1}^{D_{1}} \mu_{d_{1}} z_{d_{1} j}-\sum_{d_{2}=1}^{D_{2}} \mu_{d_{2}} z_{d_{2} j} \leq 0, j=1, \ldots, n \\
& \sum_{i_{1}=1}^{I_{1}} \nu_{i_{1}} x_{i_{1} 0}+\sum_{i_{2}=1}^{I_{2}} \nu_{i_{2}} x_{i_{2} 0}=1 \\
& \sum_{r=1}^{S} \mu_{r} y_{r 0}=\theta_{0}^{\text {overall } *} \\
& \mu_{r}, \mu_{d_{1}}, \mu_{d_{2}}, \nu_{i_{1}}, \nu_{i_{2}} \geq 0, r=1, \ldots, S, d_{1}=1, \ldots, D_{1}, d_{2}=1, \ldots, D_{2}, \\
& i_{1}=1, \ldots, I_{1}, i_{2}=1, \ldots, I_{2} .
\end{aligned}
$$

The minimal efficiency of PMS can be then calculated as $\theta_{0}^{2-}=\frac{\theta_{0}^{\text {overall* }}}{\theta_{0}^{1+}}$ according to formula (2.7). Note that the efficiency of PMS $\theta_{0}^{2-}$ denoted with " $2-$ " is to indicate that this stage is not given the pre-emptive priority. 
Instead, the maximal efficiency of PMS can be evaluated by model (2.11), when pre-emptive priority is to be given this stage.

$$
\begin{aligned}
\theta_{0}^{2+}=\max & \sum_{r=1}^{S} \mu_{r} y_{r 0} \\
\text { s.t. } \quad & \sum_{d_{1}=1}^{D_{1}} \mu_{d_{1}} z_{d_{1} j}-\sum_{i_{1}=1}^{I_{1}} \nu_{i_{1}} x_{i_{1} j} \leq 0, \quad j=1, \ldots, n \\
& \sum_{d_{2}=1}^{D_{2}} \mu_{d_{2}} z_{d_{2} j}-\sum_{i_{2}=1}^{I_{2}} \nu_{i_{2}} x_{i_{2} j} \leq 0, j=1, \ldots, n \\
& \sum_{r=1}^{S} \mu_{r} y_{r j}-\sum_{d_{1}=1}^{D_{1}} \mu_{d_{1}} z_{d_{1} j}-\sum_{d_{2}=1}^{D_{2}} \mu_{d_{2}} z_{d_{2} j} \leq 0, j=1, \ldots, n \\
& \sum_{d_{1}=1}^{D_{1}} \mu_{d_{1}} z_{d_{1} 0}+\sum_{d_{2}=1}^{D_{2}} \mu_{d_{2}} z_{d_{2} 0}=1 \\
& \sum_{r=1}^{S} \mu_{r} y_{r 0}-\theta_{0}^{\text {overall* }} \cdot\left(\sum_{i_{1}=1}^{I_{1}} \nu_{i_{1}} x_{i_{1} 0}+\sum_{i_{2}=1}^{I_{2}} \nu_{i_{2}} x_{i_{2} 0}\right)=0 \\
& \mu_{r}, \mu_{d_{1}}, \mu_{d_{2}}, \nu_{i_{1}}, \nu_{i_{2}} \geq 0, r=1, \ldots, S, d_{1}=1, \ldots, D_{1}, d_{2}=1, \ldots, D_{2}, \\
& i_{1}=1, \ldots, I_{1}, i_{2}=1, \ldots, I_{2} .
\end{aligned}
$$

The corresponding efficiency of DCS will be $\theta_{0}^{1-}=\frac{\theta_{0}^{\text {overall } *}}{\theta_{0}^{2+}}$ according to formula $(2.7)$. In other words, $\theta_{0}^{1-}$ is the minimal efficiency of DCS with given $\theta_{0}^{\text {overall* }}$ and $\theta_{0}^{2+}$. As mentioned above, we have a unique efficiency decomposition for DCS and PMS if $\theta_{0}^{1+}=\theta_{0}^{1-}$ or $\theta_{0}^{2+}=\theta_{0}^{2-}$. If this is the case, we can decompose the optimal efficiency of DCS $\theta_{0}^{1 *}$ into the efficiencies of BS and HS.

Within DCS, if BS is to be given pre-emptive priority, model (2.12) can determine its maximal efficiency $\theta_{0}^{1.1+}$, while maintaining the efficiency of DCS at $\theta_{0}^{1 *}$.

$$
\begin{aligned}
\theta_{0}^{1.1+}=\max & \sum_{d_{1}=1}^{D_{1}} \mu_{d_{1}} z_{d_{1} 0} \\
\text { s.t. } \quad & \sum_{d_{1}=1}^{D_{1}} \mu_{d_{1}} z_{d_{1} j}-\sum_{i_{1}=1}^{I_{1}} \nu_{i_{1}} x_{i_{1} j} \leq 0, \quad j=1, \ldots, n \\
& \sum_{d_{2}=1}^{D_{2}} \mu_{d_{2}} z_{d_{2} j}-\sum_{i_{2}=1}^{I_{2}} \nu_{i_{2}} x_{i_{2} j} \leq 0, \quad j=1, \ldots, n \\
& \sum_{d_{1}=1}^{D_{1}} \mu_{d_{1}} z_{d_{1} 0}+\sum_{d_{2}=1}^{D_{2}} \mu_{d_{2}} z_{d_{2} 0}-\theta_{0}^{1 *} \cdot \sum_{i_{2}=1}^{I_{2}} \nu_{i_{2}} x_{i_{2} 0}=\theta_{0}^{1 *} \\
& \sum_{i_{1}=1}^{I_{1}} \nu_{i_{1}} x_{i_{1} 0}=1 \\
& \mu_{d_{1}}, \mu_{d_{2}}, \nu_{i_{1}}, \nu_{i_{2}} \geq 0, d_{1}=1, \ldots, D_{1}, d_{2}=1, \ldots, D_{2}, \\
& i_{1}=1, \ldots, I_{1}, i_{2}=1, \ldots, I_{2} .
\end{aligned}
$$

According to formula (2.3), the corresponding efficiency of HS is calculated as $\theta_{0}^{1.2-}=\frac{\theta_{0}^{1 *}-w_{1}^{*} \cdot \theta_{0}^{1.1+}}{w_{2}^{*}}$, where $w_{1}^{*}$ and $w_{2}^{*}$ represent optimal weights obtained from model (2.9) by way of (4). That is, these weights guarantee the optimal efficiency of the whole system and permit BS to have a maximal efficiency. When we give pre-emptive priority to HS, its maximal efficiency can be obtained by model (2.13).

$$
\begin{aligned}
\theta_{0}^{1.2+}=\max & \sum_{d_{2}=1}^{D_{2}} \mu_{d_{2}} z_{d_{2} 0} \\
\text { s.t. } & \sum_{d_{1}=1}^{D_{1}} \mu_{d_{1}} z_{d_{1} j}-\sum_{i_{1}=1}^{I_{1}} \nu_{i_{1}} x_{i_{1} j} \leq 0, \quad j=1, \ldots, n \\
& \sum_{D_{2}=1}^{D_{2}} \mu_{d_{2}} z_{d_{2} j}-\sum_{i_{2}=1}^{I_{2}} \nu_{i_{2}} x_{i_{2} j} \leq 0, \quad j=1, \ldots, n \\
& \sum_{D_{1}=1}^{D_{1}} \mu_{d_{1}} z_{d_{1} 0}+\sum_{d_{2}=1}^{D_{2}} \mu_{d_{2}} z_{d_{2} 0}-\theta_{0}^{1 *} \cdot \sum_{i_{1}=1}^{I_{1}} \nu_{i_{1}} x_{i_{1} 0}=\theta_{0}^{1 *} \\
& \sum_{i_{2}=1}^{I_{2}=1} \nu_{i_{2}} x_{i_{2} 0}=1 \\
& \mu_{d_{1}}, \mu_{d_{2}}, \nu_{i_{1}}, \nu_{i_{2}} \geq 0, d_{1}=1, \ldots, D_{1}, d_{2}=1, \ldots, D_{2}, \\
& i_{1}=1, \ldots, I_{1}, i_{2}=1, \ldots, I_{2} .
\end{aligned}
$$


The minimal efficiency of BS can be calculated as $\theta_{0}^{1.1-}=\frac{\theta_{0}^{1 *}-w_{2}^{*} \cdot \theta_{0}^{1.2+}}{w_{1}^{*}}$, where $w_{1}^{*}$ and $w_{2}^{*}$ represent optimal weights obtained from model (2.9) by way of (4). Finally, if $\theta_{0}^{1.1+}=\theta_{0}^{1.1-}$ or $\theta_{0}^{1.2+}=\theta_{0}^{1.2-}$, unique efficiency decomposition of DCS is obtained. We denote then the optimal efficiency of BS and HS as $\theta_{0}^{1.1 *}$ and $\theta_{0}^{1.2 *}$, respectively. With this procedure, we realize the unique efficiency decomposition of the overall efficiency of the banks production system into efficiencies of the BS, HS, and PMS, as well as that of DCS and PMS.

\subsection{Cooperative-Stackelberg hybrid two-stage DEA approach}

\subsubsection{Non-cooperative model in deposits collecting stage leader case}

Based on the thoughts of Stackelberg game or leader-follower DEA [23, 24], we develop a cooperativeStackelberg hybrid two-stage DEA approach to evaluate and decompose the efficiency of series-parallel banking production system.

Consider again the system as illustrated in Figure 1, we suppose that there is a preference for DCS or for PMS to managers. The stage with preference is the leader stage for which the efficiency maximization is more preferable. We firstly assume that DCS is the leader. To evaluate the efficiency of the leader stage, we propose model (2.14) with reference to model (2.5).

$$
\begin{aligned}
& \theta_{0}^{1(L) *}=\max \frac{\sum_{d_{1}=1}^{D_{1}} u_{d_{1}} z_{d_{1} 0}+\sum_{d_{2}=1}^{D_{2}} u_{d_{2}} z_{d_{2} 0}}{\sum_{i_{1}=1}^{I_{1}} v_{i_{1}} x_{i_{1} 0}+\sum_{i_{2}=1}^{I_{2}} v_{i_{2}} x_{i_{2} 0}} \\
& \text { s.t. } \frac{\sum_{d_{1}=1}^{D_{1}} u_{d_{1}} z_{d_{1} j}}{\sum_{i_{1}=1}^{I_{1}} v_{i_{1}} x_{i_{1} j}} \leq 1, j=1, \ldots, n \\
& \frac{\sum_{d_{2}=1}^{D_{2}} u_{d_{2}} z_{d_{2} j}}{\sum_{i_{2}}^{I_{2}} v_{i_{2}} x_{i_{2} j}} \leq 1, j=1, \ldots, n \\
& u_{d_{1}}, u_{d_{2}}, v_{i_{1}}, v_{i_{2}} \geq 0, d_{1}=1, \ldots, D_{1}, d_{2}=1, \ldots, D_{2}, \\
& i_{1}=1, \ldots, I_{1}, i_{2}=1, \ldots, I_{2} .
\end{aligned}
$$

where "1(L)*" signifies that DCS is the leader. By using the Charnes-Cooper transformation [7], we can transform model (2.14) into model (2.15).

$$
\begin{aligned}
\theta_{0}^{1(L) *}=\max & \sum_{d_{1}=1}^{D_{1}} \mu_{d_{1}} z_{d_{1} 0}+\sum_{d_{2}=1}^{D_{2}} \mu_{d_{2}} z_{d_{2} 0} \\
\text { s.t. } \quad & \sum_{d_{1}=1}^{D_{1}} \mu_{d_{1}} z_{d_{1} j}-\sum_{i_{1}=1}^{I_{1}} \nu_{i_{1}} x_{i_{1} j} \leq 0, \quad j=1, \ldots, n \\
& \sum_{D_{2}=1}^{D_{2}} \mu_{d_{2}} z_{d_{2} j}-\sum_{i_{2}=1}^{I_{2}} \nu_{i_{2}} x_{i_{2} j} \leq 0, \quad j=1, \ldots, n \\
& \sum_{i_{1}=1}^{I_{1}=1} \nu_{i_{1}} x_{i_{1} 0}+\sum_{i_{2}=1}^{I_{2}} \nu_{i_{2}} x_{i_{2} 0}=1 \\
& \mu_{d_{1}}, \mu_{d_{2}}, \nu_{i_{1}}, \nu_{i_{2}} \geq 0, d_{1}=1, \ldots, D_{1}, d_{2}=1, \ldots, D_{2}, \\
& i_{1}=1, \ldots, I_{1}, i_{2}=1, \ldots, I_{2} .
\end{aligned}
$$

As the follower, PMS will maximize its efficiency by taking the DCS efficiency $\theta_{0}^{1(L) *}$ as a constraint. That is, the PMS will consider the optimal weights on intermediate measures $u_{d_{1}}^{*}$ and $u_{d_{2}}^{*}$ that maintain $\theta_{0}^{1}=\theta_{0}^{1(L) *}$. Considering non-cooperative relations between DCS and PMS, we assume that $u_{d_{1}}=q \cdot \mu_{d_{1}}$ and $u_{d_{2}}=q \cdot \mu_{d_{2}}$. That is, the role and position of the intermediate measures are different in the two stages, but the business deposits and the household deposits are equally important to profits making activities in the second stage. We 
develop then model (2.16) to evaluate the efficiency of PMS.

$$
\begin{aligned}
\theta_{0}^{2(S) *}=\max \frac{\sum_{r=1}^{S} u_{r} y_{r_{0}}}{q\left(\sum_{d_{1}=1}^{D_{1}} \mu_{d_{1}} z_{d_{1} 0}+\sum_{d_{2}=1}^{D_{2}} \mu_{d_{2}} z_{d_{2} 0}\right)} \\
\text { s.t. } \frac{\sum_{r=1}^{S} u_{r} y_{r_{j}}}{q\left(\sum_{d_{1}=1}^{D_{1}} \mu_{d_{1}} z_{d_{1} j}+\sum_{d_{2}=1}^{D_{2}} \mu_{d_{2}} z_{d_{2} j}\right)} \leq 0, \quad j=1, \ldots, n \\
\\
\sum_{d_{1}=1}^{D_{1}} \mu_{d_{1}} z_{d_{1} j}-\sum_{i_{1}=1}^{I_{1}} \nu_{i_{1}} x_{i_{1} j} \leq 0, \quad j=1, \ldots, n \\
\sum_{d_{2}=1}^{D_{2}} \mu_{d_{2}} z_{d_{2} j}-\sum_{i_{2}=1}^{I_{2}} \nu_{i_{2}} x_{i_{2} j} \leq 0, \quad j=1, \ldots, n \\
\sum_{i_{1}=1}^{I_{1}=1} \nu_{i_{1}} x_{i_{1} 0}+\sum_{i_{2}=1}^{I_{2}} \nu_{i_{2}} x_{i_{2} 0}=1 \\
\sum_{D_{1}=1}^{D_{1}} \mu_{d_{1}} z_{d_{1} 0}+\sum_{d_{2}=1}^{D_{2}} \mu_{d_{2}} z_{d_{2} 0}=\theta_{0}^{1(L) *} \\
q, \mu_{r}, \mu_{d_{1}}, \mu_{d_{2}}, \nu_{i_{1}}, \nu_{i_{2}} \geq 0, r=1, \ldots, S, d_{1}=1, \ldots, D_{1}, d_{2}=1, \ldots, D_{2}, \\
i_{1}=1, \ldots, I_{1}, i_{2}=1, \ldots, I_{2},
\end{aligned}
$$

where "2(S)*" signifies that PMS is the follower. Let $\mu_{r}=\frac{u_{r}}{q}, r=1, \ldots, S$, model $(2.16)$ is then equivalent to model (2.17).

$$
\begin{aligned}
& \theta_{0}^{2(S) *}=\max \frac{\sum_{r=1}^{S} \mu_{r} y_{r_{0}}}{\theta_{0}^{1(L) *}} \\
& \text { s.t. } \quad \sum_{r=1}^{S} \mu_{r} y_{r j}-\left(\sum_{d_{1}=1}^{D_{1}} \mu_{d_{1}} z_{d_{1} j}+\sum_{d_{2}=1}^{D_{2}} \mu_{d_{2}} z_{d_{2} j}\right) \leq 0, \quad j=1, \ldots, n \\
& \sum_{d_{1}=1}^{D_{1}} \mu_{d_{1}} z_{d_{1} j}-\sum_{i_{1}=1}^{I_{1}} \nu_{i_{1}} x_{i_{1} j} \leq 0, \quad j=1, \ldots, n \\
& \sum_{d_{2}=1}^{D_{2}} \mu_{d_{2}} z_{d_{2} j}-\sum_{i_{2}=1}^{I_{2}} \nu_{i_{2}} x_{i_{2} j} \leq 0, \quad j=1, \ldots, n \\
& \sum_{i_{1}=1}^{I_{1}=1} \nu_{i_{1}} x_{i_{1} 0}+\sum_{i_{2}=1}^{I_{2}=1} \nu_{i_{2}} x_{i_{2} 0}=1 \\
& \sum_{D_{1}=1}^{D_{1}} \mu_{d_{1}} z_{d_{1} 0}+\sum_{d_{2}=1}^{D_{2}} \mu_{d_{2}} z_{d_{2} 0}=\theta_{0}^{1(L) *} \\
& \mu_{r}, \mu_{d_{1}}, \mu_{d_{2}}, \nu_{i_{1}}, \nu_{i_{2}} \geq 0, r=1, \ldots, S, d_{1}=1, \ldots, D_{1}, d_{2}=1, \ldots, D_{2}, \\
& i_{1}=1, \ldots, I_{1}, i_{2}=1, \ldots, I_{2} .
\end{aligned}
$$

Note that $\theta_{0}^{1(L) *} \cdot \theta_{0}^{2(S) *}=\sum_{r=1}^{S} \mu_{r}^{*} y_{r_{0}}$ at optimality with $\sum_{i_{1}=1}^{I_{1}} \nu_{i_{1}}^{*} x_{i_{1} 0}+\sum_{i_{2}=1}^{I_{2}} \nu_{i_{2}}^{*} x_{i_{2} 0}=1$. That is, $\theta_{0}^{1(L) *}$. $\theta_{0}^{2(S) *}=\max \frac{\sum_{r=1}^{S} \mu_{r}^{*} y_{r 0}}{\sum_{i_{1}=1}^{I_{1}=1} v_{i_{1}}^{*} x_{i_{1} 0}+\sum_{i_{2}=1}^{I_{2}} v_{i_{2}}^{*} x_{i_{2} 0}}$ with the optimal solutions to model (2.17).

\subsubsection{Non-cooperative model in profit making stage leader case}

If we assume that PMS is the leader, the efficiency of DCS is computed subject to the requirement that the efficiency of PMS is fixed at the optimal level. We calculate the efficiency of PMS with the following standard CCR model (2.18).

$$
\begin{aligned}
& \theta_{0}^{2(L) *}=\max \frac{\sum_{r=1}^{S} u_{r} y_{r 0}}{\sum_{d_{1}=1}^{D_{1}} u_{d_{1}} z_{d_{1} 0}+\sum_{d_{2}=1}^{D_{2}} u_{d_{2}} z_{d_{2} 0}} \\
& \text { s.t. } \frac{\sum_{r=1}^{S} u_{r} y_{r j}}{\sum_{d_{1}=1}^{D_{1}} u_{d_{1}} z_{d_{1} j}+\sum_{d_{2}=1}^{D_{2}} u_{d_{2}} z_{d_{2} j}} \leq 1, \quad j=1, \ldots, n \\
& u_{r}, u_{d_{1}}, u_{d_{2}} \geq 0, r=1, \ldots, S, d_{1}=1, \ldots, D_{1}, d_{2}=1, \ldots, D_{2},
\end{aligned}
$$


where "2(L)*" signifies that PMS is the leader. The linear model will be the following model (2.19) by using Charnes-Cooper transformation [7].

$$
\begin{aligned}
& \theta_{0}^{2(L) *}= \max \sum_{r=1}^{S} \mu_{r} y_{r 0} \\
& \text { s.t. } \sum_{r=1}^{S} \mu_{r} y_{r j}-\left(\sum_{d_{1}=1}^{D_{1}} \mu_{d_{1}} z_{d_{1} j}+\sum_{d_{2}=1}^{D_{2}} \mu_{d_{2}} z_{d_{2} j}\right) \leq 0, \quad j=1, \ldots, n \\
& \sum_{d_{1}=1}^{D_{1}} \mu_{d_{1}} z_{d_{1} 0}+\sum_{d_{2}=1}^{D_{2}} \mu_{d_{2}} z_{d_{2} 0}=1 \\
& \mu_{r}, \mu_{d_{1}}, \mu_{d_{2}} \geq 0, r=1, \ldots, S, d_{1}=1, \ldots, D_{1}, d_{2}=1, \ldots, D_{2},
\end{aligned}
$$

when $\theta^{2(L) *}$ is obtained, the DCS efficiency can be evaluated via model (2.20).

$$
\begin{aligned}
\theta_{0}^{1(S) *}=\max \frac{q\left(\sum_{d_{1}=1}^{D_{1}} u_{d_{1}} z_{d_{1} 0}+\sum_{d_{2}=1}^{D_{2}} u_{d_{2}} z_{d_{2} 0}\right)}{\sum_{i_{1}=1}^{I_{1}} v_{i_{1}} x_{i_{1} 0}+\sum_{i_{2}=1}^{I_{2}} v_{i_{2}} x_{i_{2} 0}} \\
\text { s.t. } \frac{q \sum_{d_{1}=1}^{D_{1}} u_{d_{1}} z_{d_{1} j}}{\sum_{i_{1}=1}^{I_{1}} v_{i_{1}} x_{i_{1} j}} \leq 1, \quad j=1, \ldots, n \\
\frac{q \sum_{d_{2}=1}^{D_{2}} u_{d_{2}} z_{d_{2} j}}{\sum_{i_{2}}^{I_{2}} v_{i_{2}} x_{i_{2} j}} \leq 1, \quad j=1, \ldots, n \\
\sum_{r=1}^{S} \mu_{r} y_{r j}-\left(\sum_{d_{1}=1}^{D_{1}} \mu_{d_{1}} z_{d_{1} j}+\sum_{d_{2}=1}^{D_{2}} \mu_{d_{2}} z_{d_{2} j}\right) \leq 0, j=1, \ldots, n \\
\sum_{d_{1}=1}^{D_{1}} \mu_{d_{1}} z_{d_{1} 0}+\sum_{d_{2}=1}^{D_{2}} \mu_{d_{2}} z_{d_{2} 0}=1 \\
\sum_{r=1}^{S} \mu_{r} y_{r_{0}}=\theta_{0}^{2(L) *} \\
q, \mu_{r}, \mu_{d_{1}}, \mu_{d_{2}}, \nu_{i_{1}}, \nu_{i_{2}} \geq 0, r=1, \ldots, S, d_{1}=1, \ldots, D_{1}, d_{2}=1, \ldots, D_{2}, \\
i_{1}=1, \ldots, I_{1}, i_{2}=1, \ldots, I_{2},
\end{aligned}
$$

where " $1(S) *$ " signifies that DCS is the follower. Let $\nu_{i_{1}}=\frac{v_{i_{1}}}{q}, i_{1} \in I_{1}$ and $\nu_{i_{2}}=\frac{v_{i_{2}}}{q}, i_{2} \in I_{2}$, model $(2.20)$ is then equivalent to the following linear model (2.21).

$$
\begin{aligned}
& \frac{1}{\theta_{0}^{1(S) *}}=\min \sum_{i_{1}=1}^{I_{1}} \nu_{i_{1}} x_{i_{1} 0}+\sum_{i_{2}=1}^{I_{2}} \nu_{i_{2}} x_{i_{2} 0} \\
& \text { s.t. } \quad \sum_{D_{1}=1}^{D_{1}} \mu_{d_{1}} z_{d_{1} j}-\sum_{i_{1}=1}^{I_{1}} \nu_{i_{1}} x_{i_{1} j} \leq 0, \quad j=1, \ldots, n \\
& \sum_{d_{2}=1}^{D_{2}} \mu_{d_{2}} z_{d_{2} j}-\sum_{i_{2}=1}^{I_{2}} \nu_{i_{2}} x_{i_{2} j} \leq 0, j=1, \ldots, n \\
& \sum_{r=1}^{S} \mu_{r} y_{r j}-\left(\sum_{d_{1}=1}^{D_{1}} \mu_{d_{1}} z_{d_{1} j}+\sum_{d_{2}=1}^{D_{2}} \mu_{d_{2}} z_{d_{2} j}\right) \leq 0, j=1, \ldots, n \\
& \sum_{d_{1}=1}^{D_{1}} \mu_{d_{1}} z_{d_{1} 0}+\sum_{d_{2}=1}^{D_{2}} \mu_{d_{2}} z_{d_{2} 0}=1 \\
& \sum_{r=1}^{S} \mu_{r} y_{r 0}=\theta_{0}^{2(L) *} \\
& \mu_{r}, \mu_{d_{1}}, \mu_{d_{2}}, \nu_{i_{1}}, \nu_{i_{2}} \geq 0, r=1, \ldots, S, d_{1}=1, \ldots, D_{1}, d_{2}=1, \ldots, D_{2}, \\
& i_{1}=1, \ldots, I_{1}, i_{2}=1, \ldots, I_{2} .
\end{aligned}
$$

Note that from model $(2.21)$, we have $\theta_{0}^{1(S) *} \cdot \theta_{0}^{2(L) *}=\frac{\sum_{r=1}^{S} \mu_{r}^{*} y_{r 0}}{\sum_{i_{1}=1}^{I_{1}} v_{i_{1}}^{*} x_{i_{1} 0}+\sum_{i_{2}=1}^{I_{2}} v_{i_{2}}^{*} x_{i_{2} 0}}$ at optimality, and we observe that $\theta_{0}^{1(L) *} \cdot \theta_{0}^{2(S) *}=\frac{\sum_{r=1}^{S} \mu_{r}^{*} y_{r 0}}{\sum_{i_{1}=1}^{I_{1}} v_{i_{1}}^{*} x_{i_{1} 0}+\sum_{i_{2}=1}^{I_{2}} v_{i_{2}}^{*} x_{i_{2} 0}}$ in model $(2.17)$. That is, the leader-follower game DEA models imply an efficiency decomposition approach for the parallel-series system. The overall efficiency of the parallelseries banking production system is thus the product of DCS efficiency and PMS efficiency. 
Note further that, $\theta_{0}^{1(L) *}$ and $\theta_{0}^{2(S) *}$ in DCS leader case, and $\theta_{0}^{1(S) *}$ and $\theta_{0}^{2(L) *}$ in PMS case, are all optimal values to linear programs. Therefore, the efficiency decomposition is unique, and the result is not affected by possible multiple optimal solutions. However, the efficiency decomposition of deposits collecting stage may not be the same in the DCS leader case and the PMS leader case.

\subsubsection{Efficiency decomposition of deposits collecting stage in cooperative-Stackelberg case}

Note that DCS is composed of BS and HS. We suppose that the two sub-systems operate cooperatively, or there is no priority between different sources of deposits collecting. We propose the following procedure of addressing the efficiency decomposition of the DCS.

We develop model (2.22) by reference to model (2.12) to evaluate the optimal efficiency of BS, which is to be given pre-emptive priority, while maintaining the efficiency of DCS at $\theta_{0}^{1(L) *}$, i.e., in the DCS leader case.

$$
\begin{aligned}
& \theta_{0}^{1.1(1(L))+}=\max \sum_{d_{1}=1}^{D_{1}} \mu_{d_{1}} z_{d_{1} 0} \\
& \text { s.t. } \sum_{D_{1}=1}^{D_{1}} \mu_{d_{1}} z_{d_{1} j}-\sum_{i_{1}=1}^{I_{1}} \nu_{i_{1}} x_{i_{1} j} \leq 0, \quad j=1, \ldots, n \\
& \sum_{d_{2}=1}^{D_{2}} \mu_{d_{2}} z_{d_{2} j}-\sum_{i_{2}=1}^{I_{2}} \nu_{i_{2}} x_{i_{2} j} \leq 0, \quad j=1, \ldots, n \\
& \sum_{d_{1}=1}^{D_{1}} \mu_{d_{1}} z_{d_{1} 0}+\sum_{d_{2}=1}^{D_{2}} \mu_{d_{2}} z_{d_{2} 0}-\theta_{0}^{1(L) *} \cdot \sum_{i_{2}=1}^{I_{2}} \nu_{i_{2}} x_{i_{2} 0}=\theta_{0}^{1(L) *} \\
& \sum_{i_{1}=1}^{I_{1}} \nu_{i_{1}} x_{i_{1} 0}=1 \\
& \mu_{d_{1}}, \mu_{d_{2}}, \nu_{i_{1}}, \nu_{i_{2}} \geq 0, d_{1}=1, \ldots, D_{1}, d_{2}=1, \ldots, D_{2}, \\
& i_{1}=1, \ldots, I_{1}, i_{2}=1, \ldots, I_{2} .
\end{aligned}
$$

According to formulas (2.3), the minimal efficiency of HS can be determined as $\theta_{0}^{1.2(1(L))-}=$ $\frac{\theta_{0}^{1(L) *}-w_{1}^{1(L) *} \cdot \theta_{0}^{1.1(1(L))+}}{w_{2}^{1(L) *}}$, where $w_{1}^{1(L) *}$ and $w_{2}^{1(L) *}$ represent optimal weights obtained from model (2.15) by way of (2.4). These weights guarantee the optimal efficiency of DCS as leader and permit BS to have maximal efficiency. If we give the pre-emptive priority to HS, the optimal efficiency of HS can be obtained from model (2.23).

$$
\begin{aligned}
& \theta_{0}^{1.2(1(L))+}=\max \sum_{d_{2}=1}^{D_{2}} \mu_{d_{2}} z_{d_{2} 0} \\
& \text { s.t. } \sum_{D_{1}=1}^{D_{1}} \mu_{d_{1}} z_{d_{1} j}-\sum_{i_{1}=1}^{I_{1}} \nu_{i_{1}} x_{i_{1} j} \leq 0, \quad j=1, \ldots, n \\
& \sum_{d_{2}=1}^{D_{2}} \mu_{d_{2}} z_{d_{2} j}-\sum_{i_{2}=1}^{I_{2}} \nu_{i_{2}} x_{i_{2} j} \leq 0, \quad j=1, \ldots, n \\
& \sum_{d_{1}=1}^{D_{1}} \mu_{d_{1}} z_{d_{1} 0}+\sum_{d_{2}=1}^{D_{2}} \mu_{d_{2}} z_{d_{2} 0}-\theta_{0}^{1(L) *} \cdot \sum_{i_{1}=1}^{I_{1}} \nu_{i_{1}} x_{i_{1} 0}=\theta_{0}^{1(L) *} \\
& \sum_{i_{1}=1}^{I_{1}} \nu_{i_{1}} x_{i_{1} 0}=1 \\
& \mu_{d_{1}}, \mu_{d_{2}}, \nu_{i_{1}}, \nu_{i_{2}} \geq 0, d_{1}=1, \ldots, D_{1}, d_{2}=1, \ldots, D_{2}, \\
& i_{1}=1, \ldots, I_{1}, i_{2}=1, \ldots, I_{2} .
\end{aligned}
$$

Similarly, the corresponding minimal efficiency of BS can be calculated as $\theta_{0}^{1.1(1(L))-}=\frac{\theta_{0}^{1(L) *}-w_{2}^{1(L) *} \cdot \theta_{0}^{1.2(1(L))+}}{w_{1}^{1(L) *}}$, where $w_{1}^{1(L) *}$ and $w_{2}^{1(L) *}$ represent optimal weights obtained from model $(2.15)$ by way of $(2.4)$. If $\theta_{0}^{1.1(1(L))+}=$ $\theta_{0}^{1.1(1(L))-}$ or $\theta_{0}^{1.2(1(L))+}=\theta_{0}^{1.2(1(L))-}$, unique decomposition of DCS is obtained. We denote the optimal efficiency scores of BS and HS as $\theta_{0}^{1.1(1(L)) *}$ and $\theta_{0}^{1.2(1(L)) *}$, respectively. With this procedure, the unique efficiency decomposition of DCS into the efficiencies of BS and HS is realized in the DCS leader case. 
When PMS is the leader, we develop models (2.24) and (2.25) to calculate the efficiencies of BS and HS, with pre-emptive priority given respectively.

$$
\begin{aligned}
& \theta_{0}^{1.1(2(L))+}=\max \sum_{d_{1}=1}^{D_{1}} \mu_{d_{1}} z_{d_{1} 0} \\
& \text { s.t. } \sum_{d_{1}=1}^{d_{1} \overline{\bar{D}}_{1}} \mu_{d_{1}} z_{d_{1} j}-\sum_{i_{1}=1}^{I_{1}} \nu_{i_{1}} x_{i_{1} j} \leq 0, \quad j=1, \ldots, n \\
& \sum_{d_{2}=1}^{D_{2}} \mu_{d_{2}} z_{d_{2} j}-\sum_{i_{2}=1}^{I_{2}} \nu_{i_{2}} x_{i_{2} j} \leq 0, \quad j=1, \ldots, n \\
& \begin{array}{l}
\sum_{d_{1}=1}^{D_{1}} \mu_{d_{1}} z_{d_{1} 0}+\sum_{d_{2}=1}^{D_{2}} \mu_{d_{2}} z_{d_{2} 0}-\theta_{0}^{1(S) *} \cdot \sum_{i_{2}=1}^{I_{2}} \nu_{i_{2}} x_{i_{2} 0}=\theta_{0}^{1(S) *} \\
\sum_{i_{1}=1}^{I_{1}} \nu_{i_{1}} x_{i_{1} 0}=1
\end{array} \\
& \mu_{d_{1}}, \mu_{d_{2}}, \nu_{i_{1}}, \nu_{i_{2}} \geq 0, d_{1}=1, \ldots, D_{1}, d_{2}=1, \ldots, D_{2} \text {, } \\
& i_{1}=1, \ldots, I_{1}, i_{2}=1, \ldots, I_{2} \text {. } \\
& \theta_{0}^{1.2(2(L))+}=\max \sum_{d_{2}=1}^{D_{2}} \mu_{d_{2}} z_{d_{2} 0} \\
& \text { s.t. } \sum_{d_{1}=1}^{d_{2} \overline{\bar{D}}_{1}} \mu_{d_{1}} z_{d_{1} j}-\sum_{i_{1}=1}^{I_{1}} \nu_{i_{1}} x_{i_{1} j} \leq 0, \quad j=1, \ldots, n \\
& \sum_{d_{2}=1}^{D_{2}} \mu_{d_{2}} z_{d_{2} j}-\sum_{i_{2}=1}^{I_{2}} \nu_{i_{2}} x_{i_{2} j} \leq 0, \quad j=1, \ldots, n \\
& \sum_{d_{1}=1}^{D_{1}} \mu_{d_{1}} z_{d_{1} 0}+\sum_{d_{2}=1}^{D_{2}} \mu_{d_{2}} z_{d_{2} 0}-\theta_{0}^{1(S) *} \cdot \sum_{i_{1}=1}^{I_{1}} \nu_{i_{1}} x_{i_{1} 0}=\theta_{0}^{1(S) *} \\
& \sum_{i_{1}=1}^{I_{1}} \nu_{i_{1}} x_{i_{1} 0}=1 \\
& \mu_{d_{1}}, \mu_{d_{2}}, \nu_{i_{1}}, \nu_{i_{2}} \geq 0, d_{1}=1, \ldots, D_{1}, d_{2}=1, \ldots, D_{2} \text {, } \\
& i_{1}=1, \ldots, I_{1}, i_{2}=1, \ldots, I_{2} \text {. }
\end{aligned}
$$

According to formulas (2.3), the efficiencies of $\mathrm{HS}$ and $\mathrm{BS}$ can be determined as $\theta_{0}^{1.2(2(L))-}=\frac{\theta_{0}^{1(S) *}-w_{1}^{1(S) *} \cdot \theta_{0}^{1.1(2(L))+}}{w_{2}^{1(S) *}}$ and $\theta_{0}^{1.1(2(L))-}=\frac{\theta_{0}^{1(S) *}-w_{2}^{1(S) *} \cdot \theta_{0}^{1.2(2(L))+}}{w_{1}^{1(S) *}}$, respectively, where $w_{1}^{1(S) *}$ and $w_{2}^{1(S) *}$ represent optimal weights obtained from model $(2.15)$ by way of $(2.4)$. Finally, if $\theta_{0}^{1.1(2(L))+}=\theta_{0}^{1.1(2(L))-}$ or $\theta_{0}^{1.2(2(L))+}=\theta_{0}^{1.2(2(L))-}$, unique decomposition of DCS is obtained. We denote then the optimal efficiency scores of BS and HS as $\theta_{0}^{1.1(2(L)) *}$ and $\theta_{0}^{1.2(2(L)) *}$, respectively. With this procedure, the unique efficiency decomposition of DCS into the efficiencies of BS and HS is realized in the PMS leader case.

\section{Illustrative applichtion}

After formulating the methodological framework in the previous section, this section illustrates the proposed cooperative and cooperative-Stackelberg hybrid two-stage DEA models on the datasets of 19 main Chinese commercial banks listed in the China Stock Market.

Paradi et al. [32] proposed three approaches for variables selection in the banking performance evaluation: production approach, intermediary approach and profitability approach. From the viewpoint of production process, we regard the commercial bank using operational and capital costs $[3,44,46]$ to produce standard outputs like incomes, profits, loans, and investment returns, via deposits collected from individual consumers and business consumers. The selection of input-output variable in this study is consistent with the main literature.

As illustrated in Figure 1, for any commercial bank $j,(j=1, \ldots, 19)$ in the sample, the DCS is comprised by BS and HS in parallel, which uses Business banking operational costs $\left(x_{1_{1} j}\right)$ and Business banking capital costs $\left(x_{2_{1} j}\right)$ to generate Business deposits $\left(z_{1 j}\right)$, and uses Consumer banking operational costs $\left(x_{1_{2} j}\right)$ and Consumer banking capital costs $\left(x_{2_{2} j}\right)$ to generate Consumer deposits $\left(z_{2 j}\right)$, respectively. Then, PMS takes $z_{1 j}$ and $z_{2 j}$ as inputs to yield Net interest income $\left(y_{1 j}\right)$, Net commissions and fees income $\left(y_{2 j}\right)$, Net profit $\left(y_{3 j}\right)$, Earnings per share $\left(y_{4 j}\right)$, Total loans and advances $\left(y_{5 j}\right)$, and Investment returns $\left(y_{6 j}\right)$, which are considered as final outputs of the banking production system. 
TABLE 2. Inputs, intermediate measures and outputs of 19 commercial banks.

\begin{tabular}{|c|c|c|c|c|c|c|c|c|c|c|c|c|}
\hline Banks & $x_{1_{1}}$ & $x_{2_{1}}$ & $x_{1_{2}}$ & $x_{2_{2}}$ & $z_{1}$ & $z_{2}$ & $y_{1}$ & $y_{2}$ & $y_{3}$ & $y_{4}$ & $y_{5}$ & $y_{6}$ \\
\hline BBJ & 19679 & 2905 & 3389 & 515 & 950473 & 250360 & 39376 & 10579 & 18882 & 0.99 & 1077101 & 395 \\
\hline CSB & 1505 & 53 & 1282 & 69 & 41042 & 52244 & 4997 & 4324 & 1322 & 0.57 & 77811 & 107 \\
\hline $\mathrm{BCD}$ & 1483 & 40 & 821 & 18 & 199181 & 100732 & 7463 & 393 & 3913 & 1.2 & 143589 & 1694 \\
\hline IBCB & 190048 & 15794 & 148665 & 12964 & 9547107 & 8068894 & 522078 & 139625 & 287451 & 0.79 & 14233448 & 11927 \\
\hline CEB & 26950 & 2635 & 21531 & 1652 & 1800948 & 471717 & 60950 & 30774 & 31611 & 0.59 & 2032056 & 212 \\
\hline BGY & 1459 & 284 & 443 & 85 & 221114 & 65917 & 10861 & 1414 & 4588 & 1.97 & 7600 & 109 \\
\hline $\mathrm{BHZ}$ & 2549 & 138 & 838 & 32 & 352637 & 66488 & 12267 & 1617 & 4550 & 1.24 & 12927 & 825 \\
\hline CCSB & 166087 & 5110 & 98382 & 7974 & 8430224 & 7078489 & 452456 & 117798 & 243651 & 0.96 & 12903441 & 6411 \\
\hline BJS & 16109 & 297 & 1668 & 243 & 641999 & 187693 & 27815 & 5779 & 12016 & 1.03 & 747289 & 229 \\
\hline JRCB & 669 & 236 & 118 & 38 & 37419 & 36326 & 2100 & 53 & 758 & 0.46 & 55853 & 331 \\
\hline $\mathrm{BCM}$ & 54044 & 8667 & 40575 & 18172 & 3257639 & 1541597 & 127366 & 40551 & 70233 & 0.91 & 4456914 & 4264 \\
\hline CMSB & 37278 & 977 & 33064 & 735 & 2446634 & 523454 & 86552 & 47742 & 50922 & 1.35 & 2804307 & 2715 \\
\hline BSH & 10356 & 274 & 3449 & 218 & 651551 & 205268 & 19117 & 6256 & 15337 & 1.96 & 664022 & 9637 \\
\hline WRCB & 1496 & 191 & 204 & 28 & 37937 & 28824 & 2525 & 69 & 739 & 0.5 & 47463 & 120 \\
\hline $\mathrm{BCS}$ & 3321 & 475 & 2178 & 168 & 240319 & 84395 & 11120 & 1094 & 3985 & 1.28 & 154487 & 149 \\
\hline $\mathrm{CMB}$ & 66231 & 2930 & 59968 & 4494 & 2725823 & 1338522 & 144852 & 64018 & 70638 & 2.78 & 3565044 & 6205 \\
\hline BZZ & 1272 & 358 & 472 & 134 & 168365 & 67563 & 8106 & 1865 & 4334 & 0.8 & 128456 & 547 \\
\hline $\mathrm{BOC}$ & 130015 & 4266 & 78168 & 4719 & 7383774 & 5831228 & 338389 & 88691 & 184986 & 0.56 & 10896558 & 12155 \\
\hline $\mathrm{CCB}$ & 66337 & 3309 & 34067 & 1981 & 2874198 & 533838 & 99645 & 46858 & 42878 & 0.84 & 3196887 & 6988 \\
\hline
\end{tabular}

TABLE 3. Overall efficiency and efficiency decomposition results of cooperative models.

\begin{tabular}{llllllllllll}
\hline \hline Banks & $\theta_{0}^{\text {overall }}$ & $\theta_{0}^{1+}$ & $\theta_{0}^{2-}$ & $\theta_{0}^{1-}$ & $\theta_{0}^{2+}$ & $\theta_{0}^{1.1+}$ & $\theta_{0}^{1.2-}$ & $\theta_{0}^{1.1-}$ & $\theta_{0}^{1.2+}$ & $w_{1}^{*}$ & $w_{2}^{*}$ \\
\hline BBJ & 0.3473 & 0.3473 & 1.0000 & 0.3473 & 1.0000 & 0.3283 & 0.3641 & 0.3283 & 0.3641 & 0.467614 & 0.532386 \\
CSB & 0.2862 & 0.2862 & 1.0000 & 0.2862 & 1.0000 & 0.2012 & 0.2862 & 0.2012 & 0.2862 & 0.000020 & 0.999980 \\
BCD & 0.8625 & 1.0000 & 0.8625 & 1.0000 & 0.8625 & 1.0000 & 1.0000 & 1.0000 & 1.0000 & 0.726298 & 0.273702 \\
ICBC & 0.3527 & 0.3527 & 1.0000 & 0.3527 & 1.0000 & 0.3561 & 0.3330 & 0.3561 & 0.3330 & 0.851342 & 0.148658 \\
CEB & 0.3237 & 0.3525 & 0.9183 & 0.3525 & 0.9183 & 0.4691 & 0.1400 & 0.4691 & 0.1400 & 0.645681 & 0.354319 \\
BGY & 0.9177 & 0.9177 & 1.0000 & 0.9177 & 1.0000 & 1.0000 & 0.6539 & 1.0000 & 0.6539 & 0.762206 & 0.237794 \\
BHZ & 0.7470 & 0.8074 & 0.9251 & 0.8074 & 0.9252 & 1.0000 & 0.5978 & 1.0000 & 0.5978 & 0.521179 & 0.478821 \\
CCSB & 0.3938 & 0.3972 & 0.9915 & 0.3972 & 0.9915 & 0.3763 & 0.4520 & 0.3763 & 0.4520 & 0.724530 & 0.275470 \\
BJS & 0.4912 & 0.4912 & 1.0000 & 0.4912 & 1.0000 & 0.4341 & 0.5653 & 0.4341 & 0.5653 & 0.565066 & 0.434934 \\
JRCB & 0.7319 & 0.8793 & 0.8324 & 0.8793 & 0.8324 & 0.3691 & 1.0000 & 0.3691 & 1.0000 & 0.191378 & 0.808622 \\
BCM & 0.2932 & 0.4060 & 0.7220 & 0.4059 & 0.7222 & 0.4064 & 0.1234 & 0.4064 & 0.1234 & 0.998750 & 0.001250 \\
CMSB & 0.3672 & 0.3680 & 0.9977 & 0.3680 & 0.9977 & 0.5029 & 0.1288 & 0.5029 & 0.1288 & 0.639421 & 0.360579 \\
BSH & 0.4775 & 0.4775 & 1.0000 & 0.4775 & 1.0000 & 0.4775 & 0.4019 & 0.4775 & 0.4017 & 0.999949 & 0.000051 \\
WRCB & 0.6054 & 0.7289 & 0.8306 & 0.7289 & 0.8306 & 0.1746 & 0.7289 & 0.1748 & 0.7289 & 0.000022 & 0.999978 \\
BCS & 0.3025 & 0.3517 & 0.8601 & 0.3517 & 0.8601 & 0.4933 & 0.2472 & 0.4933 & 0.2472 & 0.424832 & 0.575168 \\
CMB & 0.2531 & 0.2711 & 0.9337 & 0.2711 & 0.9337 & 0.3007 & 0.1436 & 0.3007 & 0.1436 & 0.811664 & 0.188336 \\
BZZ & 0.8002 & 0.8002 & 1.0000 & 0.8002 & 1.0000 & 0.8734 & 0.5035 & 0.8734 & 0.5035 & 0.802269 & 0.197731 \\
BOC & 0.4223 & 0.4474 & 0.9437 & 0.4474 & 0.9438 & 0.4201 & 0.5095 & 0.4201 & 0.5095 & 0.694451 & 0.305549 \\
CCB & 0.2528 & 0.2611 & 0.9683 & 0.2611 & 0.9684 & 0.3146 & 0.1080 & 0.3146 & 0.1080 & 0.740825 & 0.259175 \\
Mean & 0.4857 & 0.5233 & 0.9361 & 0.5233 & 0.9361 & 0.4999 & 0.4362 & 0.4999 & 0.4632 & 0.608816 & 0.391184 \\
\hline
\end{tabular}

The data is derived from the 2017 annual reports of 19 Chinese listed commercial banks, including Bank of Beijing (BBJ), Changshu Bank (CSB), Bank of Chengdu (BCD), Industrial and Commercial Bank of China (ICBC), China Everbright Bank (CEB), Bank of Guiyang (BGY), Bank of Hangzhou (BHZ), China Construction Bank (CCSB), Bank of Jiangsu (BJS), Jiangsu Jiangyin Rural Commercial Bank (JRCB), Bank of Communications (BCM), China Minsheng Bank (CMSB), Bank of Shanghai (BSH), Wujiang Rural Commercial Bank (WRCB), Bank of Changsha (BCS), China Merchants Bank (CMB), Bank of Zhengzhou (BZZ), Bank of China (BOC) and China Citic Bank (CCB). Table 2 shows the data set.

We apply the developed cooperative and cooperative-Stackelberg hybrid two-stage DEA models to the dataset. The models are coded by Matlab2014a, and the results are reported in Tables 3, 4 and 5 . 
TABLE 4. Results of Cooperative-Stackelberg DEA model (DCS as leader).

\begin{tabular}{llllllllll}
\hline \hline Banks & $\theta_{0}^{1(L) *}$ & $\theta_{0}^{2(S) *}$ & $\theta_{0}^{\text {overall }(1 \mathrm{~L}) *}$ & $\theta_{0}^{1.1(1(L))+}$ & $\theta_{0}^{1.2(1(L))-}$ & $\theta_{0}^{1.1(1(L))-}$ & $\theta_{0}^{1.2(1(L))+}$ & $w_{1}^{1(L) *}$ & $w_{2}^{1(L) *}$ \\
\hline BBJ & 0.3640 & 0.8842 & 0.3219 & 0.3283 & 0.3641 & 0.3283 & 0.3641 & 0.000290 & 0.999710 \\
CSB & 0.2862 & 1.0000 & 0.2862 & 0.2011 & 0.2862 & 0.2012 & 0.2862 & 0.000020 & 0.999980 \\
BCD & 1.0000 & 0.8625 & 0.8625 & 1.0000 & 1.0000 & 1.0000 & 1.0000 & 0.692946 & 0.307054 \\
ICBC & 0.3561 & 0.9358 & 0.3332 & 0.3561 & 0.3330 & 0.3561 & 0.3332 & 0.997577 & 0.002423 \\
CEB & 0.4690 & 0.5954 & 0.2792 & 0.4691 & 0.1400 & 0.4691 & 0.1400 & 0.999663 & 0.000337 \\
BYG & 1.0000 & 0.6442 & 0.6442 & 1.0000 & 0.6539 & 1.0000 & 0.6519 & 0.999990 & 0.000010 \\
BHZ & 1.0000 & 0.4276 & 0.4276 & 1.0000 & 0.5978 & 1.0000 & 0.6001 & 0.999989 & 0.000011 \\
CCSB & 0.4518 & 0.3748 & 0.1694 & 0.3763 & 0.4520 & 0.3763 & 0.4520 & 0.002240 & 0.997760 \\
BJS & 0.5653 & 0.8132 & 0.4597 & 0.4328 & 0.5653 & 0.4341 & 0.5653 & 0.000148 & 0.999852 \\
JRCB & 1.0000 & 0.6823 & 0.6823 & 0.3705 & 1.0000 & 0.3691 & 1.0000 & 0.000010 & 0.999990 \\
BCM & 0.4060 & 0.7221 & 0.2932 & 0.4064 & 0.1234 & 0.4064 & 0.1234 & 0.998750 & 0.001250 \\
CMSB & 0.5028 & 0.6465 & 0.3250 & 0.5029 & 0.1288 & 0.5029 & 0.1284 & 0.999594 & 0.000406 \\
BSH & 0.4775 & 1.0000 & 0.4775 & 0.4775 & 0.4017 & 0.4775 & 0.4017 & 0.999949 & 0.000051 \\
WRCB & 0.7289 & 0.8306 & 0.6054 & 0.1758 & 0.7289 & 0.1746 & 0.7289 & 0.000022 & 0.999978 \\
BCS & 0.4933 & 0.5148 & 0.2539 & 0.4933 & 0.2472 & 0.4933 & 0.2475 & 0.999966 & 0.000034 \\
CMB & 0.3005 & 0.8088 & 0.2431 & 0.3007 & 0.1436 & 0.3007 & 0.1436 & 0.999068 & 0.000932 \\
BZZ & 0.8734 & 0.8235 & 0.7192 & 0.8734 & 0.5035 & 0.8734 & 0.5042 & 0.999987 & 0.000013 \\
BOC & 0.5094 & 0.3418 & 0.1741 & 0.4201 & 0.5095 & 0.4201 & 0.5095 & 0.001757 & 0.998243 \\
CCB & 0.3145 & 0.6155 & 0.1936 & 0.3146 & 0.1080 & 0.3146 & 0.1078 & 0.999506 & 0.000494 \\
Mean & 0.5841 & 0.7118 & 0.4080 & 0.4999 & 0.4362 & 0.4999 & 0.4362 & 0.615341 & 0.384659 \\
\hline
\end{tabular}

The second column of Table 3 reports the overall efficiency scores (Column 2) along with the efficiency decomposition results of the overall system when DCS takes priority (Columns 3 and 4), the efficiency decomposition results of the overall system when PMS takes priority (Columns 5 and 6), the efficiency decomposition results of DCS when BS is to be given pre-emptive priority (Columns 7 and 8), the efficiency decomposition results of DCS when HS is to be given pre-emptive priority (Columns 9 and 10), and the optimum weights associated with the efficiencies of BS and HS (Columns 11 and 12), respectively.

It can be seen from Table 3 that we have a unique decomposition of overall efficiency into the efficiencies of DCS and PMS for all the 19 banks. These results arise from the fact that models (2.10) and (2.11) yield identical efficiency scores for DCS or PMS whatever the priority is assigned to one of the two stages. The unique efficiency decomposition permits the cooperative hybrid two-stage DEA models to bring further to light the source of inefficiency.

We find out that the average efficiency of PMS is 0.9361, which is much higher than that of DCS (0.5233). That is to say, the commercial banks are more efficient in investment operations in general and the lower performance of DCS is probably the source of inefficiency. This result is consistent with the findings of [42] and [46], but the latters did not go deeper into the inefficient sub-stage to get more information. Therefore, it will be meaningful to move the focus of analysis to the inside of DCS. We decompose the efficiency of DCS into BS efficiency and HS efficiency. The decomposition results are reported by columns 7 to 10 in Tables 1 and 3 .

It seems that BCD, BGY, and BHZ are estimated as efficient in BS, but only two banks, BCD and JRCB, are efficient in HS. The average efficiency of BS activity is slightly higher than that of HS, and we must observe with care the individual efficiency of the banks. In fact, JRCB and WRCB are both local rural commercial banks for Chinas small cities, where household savings are relatively more important than those big banks. While for the big banks, for example, ICBC, CCSB, and BOC, the efficiencies are somewhat at a similar level for the two stages.

For most banks, the efficiency of BS appears to be the driver of DCS efficiency, because the weights associated with the efficiencies of business service operations are dominant in most cases (except CSB, JRCB, WRCB). This finding is intuitive based on the importance of business banking relative to consumer banking for most commercial banks, i.e., BS are generally accepted to have more influence on the performance of deposits collecting. 
TABLE 5. Results of Cooperative-Stackelberg DEA model (PMS as leader).

\begin{tabular}{llllllllll}
\hline \hline Banks & $\theta_{0}^{1(S) *}$ & $\theta_{0}^{2(L) *}$ & $\theta_{0}^{\text {overall }(2 \mathrm{~L}) *}$ & $\theta_{0}^{1.1(2(L))+}$ & $\theta_{0}^{1.2(2(L))-}$ & $\theta_{0}^{1.1(2(L))-}$ & $\theta_{0}^{1.2(2(L))+}$ & $w_{1}^{1(L) *}$ & $w_{2}^{1(L) *}$ \\
\hline BBJ & 0.3473 & 1.0000 & 0.3473 & 0.3283 & 0.3641 & 0.3283 & 0.3641 & 0.467604 & 0.532396 \\
CSB & 0.2862 & 1.0000 & 0.2862 & 0.2011 & 0.2862 & 0.2011 & 0.2862 & 0.000001 & 0.999999 \\
BCD & 1.0000 & 0.8625 & 0.8625 & 1.0000 & 1.0000 & 1.0000 & 1.0000 & 0.726315 & 0.273685 \\
ICBC & 0.3527 & 1.0000 & 0.3527 & 0.3561 & 0.3330 & 0.3561 & 0.3330 & 0.853895 & 0.146105 \\
CEB & 0.3249 & 0.9504 & 0.3087 & 0.4691 & 0.1400 & 0.4691 & 0.1400 & 0.561716 & 0.438284 \\
BGY & 0.9177 & 1.0000 & 0.9177 & 1.0000 & 0.6539 & 1.0000 & 0.6539 & 0.762224 & 0.237776 \\
BHZ & 0.7360 & 1.0000 & 0.7360 & 1.0000 & 0.5978 & 1.0000 & 0.5978 & 0.343616 & 0.656384 \\
CCSB & 0.3972 & 0.9961 & 0.3938 & 0.3763 & 0.4520 & 0.3763 & 0.4520 & 0.724506 & 0.275494 \\
BJS & 0.4912 & 1.0000 & 0.4912 & 0.4341 & 0.5653 & 0.4341 & 0.5653 & 0.565062 & 0.434938 \\
JRCB & 0.5754 & 1.0000 & 0.5754 & 0.3690 & 1.0000 & 0.3691 & 0.9999 & 0.672934 & 0.327066 \\
BCM & 0.2668 & 1.0000 & 0.2668 & 0.4064 & 0.1234 & 0.4064 & 0.1234 & 0.506616 & 0.493384 \\
CMSB & 0.3666 & 1.0000 & 0.3666 & 0.5029 & 0.1288 & 0.5029 & 0.1288 & 0.635491 & 0.364509 \\
BSH & 0.4775 & 1.0000 & 0.4775 & 0.4775 & 0.4017 & 0.4776 & 0.4017 & 0.999999 & 0.000001 \\
WRCB & 0.5532 & 1.0000 & 0.5532 & 0.1746 & 0.7289 & 0.1746 & 0.7289 & 0.316988 & 0.683012 \\
BCS & 0.3154 & 0.9230 & 0.2911 & 0.4933 & 0.2472 & 0.4933 & 0.2472 & 0.277190 & 0.722810 \\
CMB & 0.2464 & 1.0000 & 0.2464 & 0.3007 & 0.1436 & 0.3007 & 0.1436 & 0.654142 & 0.345858 \\
BZZ & 0.8002 & 1.0000 & 0.8002 & 0.8734 & 0.5035 & 0.8734 & 0.5035 & 0.802286 & 0.197714 \\
BOC & 0.4474 & 0.9438 & 0.4223 & 0.4201 & 0.5095 & 0.4201 & 0.5095 & 0.694642 & 0.305358 \\
CCB & 0.2525 & 1.0000 & 0.2525 & 0.3146 & 0.1080 & 0.3146 & 0.1080 & 0.699178 & 0.300822 \\
Mean & 0.4818 & 0.9827 & 0.4710 & 0.4999 & 0.4362 & 0.4999 & 0.4362 & 0.592863 & 0.407130 \\
\hline
\end{tabular}

However, it should be noticed that individual banks (JRCB and WRCB) having relatively low efficiency scores of the BS are evaluated with high efficiency scores of DCS. This result is not contradictive in the view of efficiency formation, because the efficiency contribution of HS is not significant in the efficiency of DCS for the two banks. Meanwhile, this result helps us to understand why a bank having inefficient sub-systems can be identified to be efficient in a particular stage even in the overall performance.

The detailed efficiency scores of sub-stage and sub-systems provide rich information about the sources of inefficiency. That is, the operation inefficiency comes from DCS for most of the commercial banks, and the efficiency of BS generally plays an important role in the efficiency formation of the DCS. Such information can help decision makers to meliorate more precisely the local or overall performance of the banking production system.

The results are obtained from our proposed cooperative approach with the assumption that none of the two stages has priority in operation efficiency maximization. Beyond these, our approach provides a set of cooperative-Stackelberg DEA models to evaluate and decompose the efficiency of the same banking production system in a non-full cooperation case. The efficiency scores are presented in Tables 4 and 5 .

In Tables 4 and 5, the first three columns report the efficiency scores of DCS and PMS along with the efficiency of the overall system in the cases of DCS as the leader and PMS as the leader, respectively. The last six columns show the efficiency decomposition of DCS and the optimum weights for BS calculated by cooperative-Stackelberg DEA models. We primarily notice that there are no overall efficient banks no matter which stage is the leader.

As Tables 4 and 5 show, when DCS is the leader, the average overall efficiency is 0.4080 , which is lower than that (0.4710) in PMS as leader case. The main reason given for this is that PMS is significantly more efficient when it is the leader (14 efficient banks), even if the average efficiency of DCS is lowered.

Besides, the means of overall efficiency in the cooperative-Stackelberg case with different leaders are both lower than those of overall efficiency in the cooperative approach. These results suggest that in our application, the performance of PMS is relatively dominant in the overall efficiency formation for most of the commercial banks, and non-cooperation relations between DCS and PMS will probably decrease the overall efficiency of the banking systems. 
We also notice that BS and HS are carried out in parallel and undertaken independently within the DCS. This fact leads to the result that the efficiency decompositions of DCS are largely the same in the cooperative approach and in the cooperative-Stackelberg approach.

Nevertheless, testing the last two columns in Tables 4 and 5, we find out that the weights associated with the efficiencies of BS and those of HS are quietly different. The mean of the weights associated with BS efficiency is evidently greater than the mean of the weights associated with the efficiency of HS in the cooperative-Stackelberg approach. This result is consistent with that in the cooperative situation, which verifies the dominant position of business saving services in DCS for commercial banks.

Several managerial insights into the operating efficiency management of commercial banks are summarized as follows. Firstly, the source of operating inefficiency exists in DCS for most of the commercial banks, and the managers should pay more attention to improve the efficiency of this stage. Secondly, the efficiency of BS system seems to be the driver of DCS, that is to say, the BS system are relatively more important than those of HS system from the perspective of operating efficiency management.

Finally, it should be noted that, when PMS is the leader, the overall efficiency scores of the commercial banks evaluated by the cooperative-Stackelberg approach are closest to the results in the cooperative approach, which are at a relatively optimal level. This result implies that the commercial banks should prefer to a cooperative operating system, which permits to achieve the optimal overall efficiency, and they should give priority to PMS when there is conflict between DCS and PMS.

\section{Conclusion}

Based on the series structure of the banks production process, the classic two-stage DEA model has a good fit for efficiency evaluation and decomposition. But this approach has generally lost sight of the performance of parallel operations inside sub-stages, and relations between two stages are normally limited to be cooperative or competitive. The results and information issued from classic two-stage DEA models are abundant but not rich enough.

In this paper, we develop a set of cooperative and cooperative-Strackelberg hybrid two-stage DEA models to assess the operating efficiency of commercial banks. The core points of this study and the main differences of our models with those that proposed previously is that, we believe that DEA models could reveal more useful information if we go deep into the internal structure of the system, and that the relations of sub-systems would affect the efficiency performance of banks operating.

The proposed approach contributes in the following points to the efficiency evaluation and decomposition of system with complex internal structure. Firstly, we present a very general case where the series-parallel internal structure and the cooperative-Stackelberg game relations coexist in a two-stage production system. Secondly, we adopt a combination of additive and multiplicative DEA thoughts to calculate and decompose efficiencies of the system, which can portray efficiency formation mechanisms for systems with complex internal structure and relations. Thirdly, the cooperative game and the leader-follower game theories are incorporated, which can be applied in different scenarios of games between the sub-stages of the production system at once.

The application of our proposed DEA models to the datasets of 19 main Chinese commercial banks listed in the China Stock Market provides a comprehensive picture of the banks production system performance in cooperative and non-cooperative situations. The results reveal that the sources of inefficiency exist in DCS for most banks. There is no significant difference between the efficiency levels of BS and HS, but the efficiency of BS dominants the efficiency of DCS in most cases. The efficiency of PMS is significantly higher than that of DCS no matter in the cooperative situation or the cooperative-Stackelberg situation. The overall efficiency of the banking production system will achieve a relatively higher score when all the sub-systems operate cooperatively, however, non-cooperation relation between sub-stages will probably decrease the overall efficiency performance.

There are several possible future research directions that can be drawn from this study. Firstly, the proposed approach is developed under the constant returns to scale (CRS) assumption. Future work may consider how to build the models under the variable returns to scale (VRS) assumption while tanking the complex internal 
structure of production system. Secondly, the undesirable outputs and uncertainty are not discussed in the proposed approach. It would be very interesting and significant to dig deeper into these aspects. Finally, the complexity of the production system can be extended to the problems of resource allocations to sub-stages within the operating system. Therefore, it becomes natural to think about how the resource allocations within the system would influence the efficiency of operating activities in the future research.

Acknowledgements. The authors wish to thank the anonymous reviewers for their constructive comments and suggestions. This work was supported by the National Natural Science Foundation of China (NSFC) under Grant 71673022.

\section{REFERENCES}

[1] S. Akther, H. Fukuyame and W.L. Weber, Estimating two-stage network slacks-based inefficiency: an application to Bangladesh banking. Omega 41 (2013) 88-96.

[2] A. Amirteimoori, S. Kordrostami and H. Azizi, Additive models for network data envelopment analysis in the presence of shared resources. Transport. Res. D 48 (2016) 411-424.

[3] Q. An, Q. Wu, X. Zhou and X. Chen, Closest target setting for two-stage network system: An application to the commercial banks in China. Expert Syst. Appl. 175 (2021) 1144799.

[4] A. Ashrafi and A.B. Jaafar, Performance measurement of two-stage production systems with undesirable factors by data envelopment analysis. J. Appl. Sci. 11 (2011) 3515-3519.

[5] A.D. Athanassopoulos, Service quality and operating efficiency synergies for management control in the provision of financial services: Evidence form Greek bank branches. Eur. J. Oper. Res. 98 (1997) 300-313.

[6] N.K. Avkiran and A. McCrystal, Sensitivity analysis of network DEA: NSBM versus NRAM. Appl. Math. Comput. 218 (2012) 11226-11239.

[7] A. Charnes and W.W. Cooper, Programming with linear fractional functional. Nav. Res. Log. 9 (1962) $181-186$.

[8] A. Charnes, W.W. Cooper and E. Rhodes, Measuring the efficiency of decision making units. Eur. J. Oper. Res. 2 (1978) 429-444.

[9] Y. Chen and J. Zhu, Measuring information technologys indirect impact on firm performance. Inform. Technol. Manag. 5 (2004) 9-22.

[10] Y. Chen, W.D. Cook, N. Li and J. Zhu, Additive efficiency decomposition in two-stage DEA. Eur. J. Oper. Res. 196 (2009) 1170-1176.

[11] Y. Chen, Y.J. Li, L. Liang, A. Salo and H. Wu, Frontier projection and efficiency decomposition in two-stage processes with slacks-based measures. Eur. J. Oper. Res. 250 (2016) 543-554.

[12] A. Ebrahimnejad, M. Tavana, F.H. Lotfi, R. Shahverdi and M. Yousefpour, A three-stage Data Envelopment Analysis model with application to banking industry. Measurement 49 (2014) 308-319.

[13] H. Fukuyama and R. Matousek, Efficiency of Turkish banking: two-stage network system: Variable returns to scale model. J. Int. Financ. Mark. Inst. Money 21 (2011) 75-91.

[14] H. Fukuyama and R. Matousek, Modeling bank performance: A network DEA approach. Eur. J. Oper. Res. 259 (2017) $721-732$.

[15] M. Hemmati, S.A. Dalghandi and H. Nazari, Measuring relative performance of banking industry using a DEA and TOPSIS. Manag. Sci. Lett. 3 (2013) 499-503.

[16] C. Kao, Network data envelopment analysis: a review. Eur. J. Oper. Res. 239 (2014) 1-16.

[17] C. Kao, Efficiency decomposition for general multi-stage systems in data envelopment analysis. Eur. J. Oper. Res. 232 (2014) 117-124.

[18] C. Kao and S.N. Hwang, Efficiency decomposition in two-stage data envelopment analysis: An application to non-life insurance companies in Taiwan. Eur. J. Oper. Res. 185 (2008) 418-429.

[19] S.A. Kourtzidis, R. Matousek and N.G. Tzeremes, Productivity growth in network models: An application to banking during the financial crisis. J. Oper. Res. Soc. 7 (2019) 111-124.

[20] H.B. Kwon and J. Lee, Two-stage production modelling of large U.S. banks: A DEA-neural network approach. Expert Syst. Appl. 42 (2015) 6758-6766.

[21] H.B. Kwon, J. Lee and K.N. White Davis, Neural network modeling for a two-stage production process with versatile variables: Predictive analysis for above-average performance. Expert Syst. Appl. 100 (2018) 120-130.

[22] H.F. Lewis and T.R. Sexton, Network DEA: Efficiency analysis of organization with complex internal structure. Comput. Oper. Res. 31 (2004) 1365-1410.

[23] L. Liang, F. Yang, W.D. Cook and J. Zhu, DEA models for supply chain efficiency evaluation. Ann. Oper. Res. 145 (2006) $35-49$.

[24] L. Liang, W.D. Cook and J. Zhu, DEA models for two-stage processes: Game approach and efficiency decomposition. Nav. Res. Log. 55 (2008) 643-653.

[25] W. Liu, Z. Zhou, C. Ma, D. Liu and W. Shen, Two-stage DEA models with undesirable input-intermediate-outputs. Omega 56 (2015) 74-87. 
[26] S. Lozano, Slacks-based inefficiency approach for general network with bad outputs: An application to the banking sector. Omega 60 (2016) 73-84.

[27] X. Luo, Evaluating the profitability and marketability efficiency of large banks C an application of data envelopment analysis. J. Bus. Res. 56 (2003) 627-635.

[28] K. Matthews, Risk management and managerial efficiency in Chinese banks: A network DEA framework. Omega 41 (2013) 207-215.

[29] S. Mehdizadeh, A. Amirteimoori, V. Charles, M.H. Behzadi and S. Kordrostami, Measuring the efficiency of two-stage network processes: A satisficing DEA approach. J. Oper. Res. Soc. 72 (2020) 354-366.

[30] S.G.J. Naini, A. Moini and M.J. Rezaee, Nash bargaining game model for two parallel stages process evaluation with shared inputs. Int. J. Adv. Manuf. Tech. 67 (2013) 475-484.

[31] J.C. Paradi and H. Zhu, A survey on bank branch efficiency and performance research with data envelopment analysis. Omega 41 (2013) 61-79.

[32] J.C. Paradi, S. Rouatt and H. Zhu, Two-stage evaluation of bank branch efficiency using data envelopment analysis. Omega 39 (2011) 99-109.

[33] B.K. Sahoo, J. Zhu, K. Tone and B.M. Klemen, Decomposing technical efficiency and scale elasticity in two-stage network DEA. Eur. J. Oper. Res. 233 (2014) 584-594.

[34] L.M. Seiford and J. Zhu, Profitability and marketability of the top 55US commercial banks. Manag. Sci. 45 (1999) $1270-1288$.

[35] M.S. Shahbazifar, R.K. Matin, M. Khounsiavash and F. Koushki, Group ranking of two-stage production units in network data envelopment analysis. RAIRO: OR 55 (2021) 1825-1840.

[36] G. Sherman and F. Gold, Bank branch operating efficiency C evaluation with data envelopment analysis. J. Bank. Finance 9 (1985) 297-315.

[37] X. Shi, Y. Li, A. Emrouznejad, J. Xie and L. Liang, Estimation of potential gains from bank mergers: A novel two-stage cost efficiency DEA model. J. Oper. Res. Soc. 68 (2017) 1045-1055.

[38] I.M. Tavakoli and A. Mostafaee, Free disposal hull efficiency scores of units with network structures. Eur. J. Oper. Res. 277 (2019) 1027-1036.

[39] K. Tone and M. Tsutsui, Network DEA: A slacks-based measure approach. Eur. J. Oper. Res. 197 (2009) $243-252$.

[40] I.E. Tsolas, Modeling bank branch profitability and effectiveness by means of DEA. Int. J. Product. Perform. Manag. 59 (2010) 432-451.

[41] P. Wanke and C. Barros, Two-Stage DEA: An application to major Brazilian banks, Expert Syst. Appl. 41 (2014) $2337-2344$.

[42] K. Wang, W. Huang, J. Wu and Y.M. Liu, Efficiency measures of the Chinese commercial banking system using an additive two-stage DEA. Omega 44 (2014) 5-20.

[43] G. Xu and Z. Zhou, Assessing the efficiency of financial supply chain for Chinese commercial banks: A two-stage AR-DEA model. Ind. Manag. Data Syst. 121 (2020) 894-920.

[44] C. Yang and H.M. Liu, Managerial efficiency in Taiwan bank branches: A network DEA, Econ. Model. 29 (2012) $450-461$.

[45] Y. Zha and L. Liang, Two-stage cooperation model with input freely distributed among the stages. Eur. J. Oper. Res. 205 (2010) 332-338.

[46] Y. Zha, N. Liang, M. Wu and Y. Bian, Efficiency evaluation of banks in China: A dynamic two-stage slacks-based measure approach. Omega 60 (2016) 60-72.

[47] Z. Zhou, L. Sun, W. Yang, W. Liu and C. Ma, A bargaining game model for efficiency decomposition in the centralized model of two-stage systems. Comput. Ind. Eng. 64 (2013) 103-108.

\section{Subscribe to Open (S20) A fair and sustainable open access model}

This journal is currently published in open access under a Subscribe-to-Open model (S2O). S2O is a transformative model that aims to move subscription journals to open access. Open access is the free, immediate, online availability of research articles combined with the rights to use these articles fully in the digital environment. We are thankful to our subscribers and sponsors for making it possible to publish this journal in open access, free of charge for authors.

\section{Please help to maintain this journal in open access!}

Check that your library subscribes to the journal, or make a personal donation to the S2O programme, by contacting subscribers@edpsciences.org

More information, including a list of sponsors and a financial transparency report, available at: https://www. edpsciences.org/en/maths-s2o-programme 